\title{
DIDACTIQUE PROFESSIONNELLE (DIDAPROF): REPERCUSSÃO PARA A PESQUISA EM TORNO DA ATIVIDADE DO PROFESSOR DE MATEMÁTICA
}

\author{
Francisco Regis Vieira Alves \\ fregis@ifce.edu.br \\ https://orcid.org/ooo0-0003-3710-1561 \\ Instituto Federal de Educação, Ciência e Tecnologia do Ceará. IFCE
}

Brasil

Recibido: 2020-05-14; Aceptado: 2020-11-29

\begin{abstract}
Resumo
A Didática Profissional (DP) se originou dos estudos desenvolvidos na França, no inicio dos anos 90, com forte teor de interesse endereçado para os processos de aprendizagem e formação de adultos, circunstanciados pelo ambiente de atividades profissionais. Por outro lado, registramos algumas décadas de tradição de estudos desenvolvidos no Brasil, balizados pelos pressupostos da Didática da Matemática (DM). Com origem nesses dois aportes teóricos clássicos, o presente trabalho apresenta uma inédita proposta teórica de complementaridade, objetivando o uso para investigação, com interesse na atividade e aquisição da competência profissional do professor de Matemática. Um elemento que se sobressai dessa proposta se revela pela interpretação cognitivista dos fenômenos originados da significação das atividades especializadas e do prório processo de aprendizagem do trabalhador (do professor de Matemática). Por conseguinte, o trabalho aponta, de forma clara, um fio condutor significante para o desenvolvimento de ulteriores investigações no Brasil, balizadas tanto pela (DP) e pela (DM), objetivando a concepção de uma Engenharia de Formação e a pesquisa em torno da atividade do professor.

Palavras-chave: Didática Profissional, Didática da Matemática, Competência profissional, Trabalho do professor.

\section{PROFESSIONAL DIDACTICS (DIDAPROF): REPERCUSSION FOR THE RESEARCH AROUND THE ACTIVITY OF THE TEACHER OF MATHEMATICS}

\begin{abstract}
The Professional Didactics (DP) originated from the studies developed in France in the early 1990s, with a strong content of interest addressed to the processes of adult learning and training, circumstantiated by the environment of professional activities. On the other hand, we recorded some decades of tradition of studies developed in Brazil, based on the presuppositions of Didactics of Mathematics (DM). Based on these two classic theoretical contributions, the present work presents an unprecedented theoretical proposal of complementarity, aiming the use for research, with interest in the activity and acquisition of the professional competence of the Mathematics teacher. An element that stands out from this proposal is revealed by the cognitivist interpretation of the phenomena originated from the meaning of specialized activities and the worker's early learning process (from the Mathematics teacher). Therefore, the work clearly indicates a guideline for the development of further investigations in Brazil, marked by
\end{abstract}


both (DM) and (DP), aiming at the design of a Engineering of profissionalization and the research in around of the teacher.

Keywords: Profissional didactics, Didactics of Mathematics, Professional competence, Tearchr's work.

\section{Introdução}

Quando tomamos como referência a pesquisa desenvolvida na tradição francesa, que se tornou conhecida em nosso país como Didática da Matemática (DM), podemos constatar algumas décadas virtuosas de sua influência e que concorreu para o aperfeiçoamento e a compreensão de uma vasta série de fenômenos eminentemente derivados do ensino e da aprendizagem de conteúdos matemáticos específicos. De modo inequívoco, a (DM), por intermédio da indicação e da adoção de determinados corpus teóricos como, por exemplo, a Engenharia Didática (ED) e a Teorias das Situações (TS) (Brousseau, 1986a) proporcionou um ponto de vista pioneiro, visando uma apreciação pormenorizada dos aspectos originados das interações dos elementos do trinômio didático clássico: estudante - professor - saber.

Nesse sentido, recordamos a pesquisa em Didática da Matemática (DM), no contexto do ensino francês que, ao final dos anos 60 e início dos anos 70, reforçou a ideia sobre a necessidade precípua de estudar os fenômenos de ensino de Matemática, a partir de um ponto de vista pedagógico, bem como uma reflexão aprofundada e necessária sobre o mesmo. Nesse cenário, divisamos um interesse de pesquisa intrinsecamente condicionado por um campo epistêmico, cuja essência se mostra influenciada e, por que não mencionar, condicionada pela própria natureza do saber matemático científico (ALVES, 2018a; 2019; 2020).

No ambiente europeu, podemos ainda divisar o emprego de outras teorias objetivando o estudo sistemático dos principais fenômenos de ensino, decorrentes e atinentes ao real funcionamento da sala de aula. Para exemplificar, além da Engenharia Didática (ED) e da (TS), Perrin-Glorian e Bellemain (2016) comentam ainda, por exemplo, o emprego da dialética instrumento - objeto (Douady, 1987) e o jogo de quadros, como quadros teóricos aplicados aos estudos e a pesquisa, desde os anos 80 e que concorreram para uma tradição investigativa ulterior e sua adoção marcante em caráter de complementaridade, visando o desenvolvimento de uma pesquisa sistemática e, por conseguinte, o reconhecimento gradual de uma comunidade internacional de especialistas (ARTIGUE, 1995; ARTIGUE e PERRIN-GLORIAN, 1991; ARTIGUE, 2015; PERRIN-GRORIAN e BELLEMAIN, 2016, MARGOLINAS e DRIJVERS, 2015; ROBINET, 1983). 
Não obstante, ao passar do tempo, com origem em um movimento ou mecanismo natural de aperfeiçoamento dos pressupostos das teorias fundantes e, ainda, a partir de um ajuste fino e imprescindível decorrente de um olhar investigativo que se alimenta intrisecamente dos resultados crescentes das pesquisas acumuladas na área e, ainda, desenvolvidas em vários paises, ocorreram questionamentos concernentes ao processo de aperfeiçoamento e evolução de determinados elementos que, em maior ou em menor substância, derivam de um cenário envolvendo um caráter de complementaridade de uso de várias teorias e, em nosso caso, acentuamos o uso standard da (ED) e da (TS) em pesquisa. Nesse sentido, observamos as ponderações de Perrin-Glorian e Bellemain (2016) quando acentuam a dialética entre a teoria (engenharia) e o viés contigencial das situações (e modelos) de interesse para a pesquisa.

Les situations doivent tenir compte à la fois de l'organisation des mathématiques, des possibilités d'apprentissage des élèves et des conditions d'enseignement des professeurs. Ces situations sont des modèles du fonctionnement des mathématiques dans les conditions de l'enseignement. C'est la théorie qui permet de faire l'analyse a priori des situations et c'est la réalisation de l'ingénierie didactique qui confronte cette théorie à la contingence. (PERRINGLORIAN e BELLEMAIN, 2016, p. 5).

No excerto acima divisamos três componentes essenciais atinentes à situação de ensino, a saber: a organização matemática (um campo epistêmico definido), a aprendizagem dos estudantes (campo cognitivo) e as condições de ensino dos professores de Matemática. Os demais elementos apontados por Perrin-Glorian e Bellemain (2016) se mostram recorrentemente contemplados nos estudos balizados por uma Engenharia Didática (ED). Não obstante, segundo alguns argumentos e o entendimento que temos assinalado em nossos trabalhos (ALVES, 2018a; 2018b; 2018c; 2018d, 2018e; 2019; 2020), ensejamos acentuar o componente das condições de ensino e da competência do professor de Matematica e, acrescentamos, da eficiência do cumprimento de atividades-tarefas especializadas dos professores, visando o ensino de Matemática e que, irremediavelmente, dependem da evolução de sua experiência profissional, circunstanciada pelo seu campo profissional.

Mais uma vez, no contexto discutido abaixo por Perrin-Glorian e Bellemain (2016), vislumbramos que a noção de competência profissional do professor, a noção do exercício do métier de modo eficiente, que se apresenta como uma variável não trivial do sistema de ensino, 
mediante o emprego naturalista ou a concepção/desenvolvimento de uma (ED) visando a formação de professores de Matemática. Com efeito, podemos observar que:

La préoccupation de l'usage des résultats des recherches dans l'enseignement ordinaire transparaît dans les travaux dont nous venons de parler. Les difficultés de transmission des ingénieries didactiques et les besoins de la formation des maîtres ont aussi fait apparaître la nécessité d'étudier de plus près le fonctionnement de l'enseignement ordinaire du point de vue des contraintes institutionnelles (y compris sociales) cadrant l'exercice du métier d'enseignant et de la conduite de la classe. Ces recherches se sont déroulées en général a partir d'observations naturalistes plutôt que d'ingénieries didactiques. Cependant la frontière entre observation naturaliste et ingénierie didactique n'est pas toujours aussi nette qu'il y paraît et l'ingénierie didactique (ou l'adaptation de produits issus d'une ingénierie didactique préalable) a aussi été utilisée comme moyen d'étude de l'enseignement ordinaire et comme moyen de formation des maîtres. (PERRINGLORIAN e BELLEMAIN, 2016, p. 36)

Urge observar o desenvolvimento de engenharias prolongadas na França envolvendo uma quantidade representativa de estudantes, um grupo considerável (multidisciplinar) de pesquisadores e professores demarcando, assim, uma identidade ímpar para a pesquisa desenvolvida no campo da Didática da Matemática (DM). Como já mencionamos, ao passar do tempo, vários especialistas (MARGOLINAS, 2005; PERRIN-GLORIAN, 2011) insistem sobre uma discussão dos próprios fundamentos assumidos há décadas e que, por intermédio de um processo endógeno de aperfeiçoamento necessário e de especialização, pode ser observado no interior de qualquer campo científico investigativo (ALVES e ALVES DIAS, 2017; ALVES e CATARINO, 2017; ALVES, 2016; 2018d).

Dessa forma, diante da constatação de um pensamento científico evolutivo no interior da (DM) acentuamos a necessidade de uma discussão e a consideração sobre os próprios processos de aprendizagem situada do professor de Matemática no trabalho, sobre uma apreciação pormenorizada dos itinerários de desenvolvimento de tarefas cotidianas, quer sejam no plano da sala de aula, no plano do posto de trabalho (poste de travail) e, por fim, no plano de um sistema de ensino e de sua profissionalização (ALVES, 2018a; 2018b; 2019; 2020).

A partir de um ponto de vista afetado pelo argumento anterior declaramos, no presente trabalho, uma discussão expressiva sobre os fundamentos da Didática Profissional (DP) (Didactique Professionneles) que possui um marco evolutivo decorrente dos estudos da Psicologia Ergonômica, dos estudos da Psicologia do Trabalho da vertente francesa e, ainda, 
dos estudos visando a aprendizagem e a formação de adultos, com marco histórico identificado ao final dos anos 80 e meados dos anos 90. Como buscaremos objetivar, nas seções vindouras, a (DP) proporcionará vislumbrarmos o papel do trabalhador e, de modo particular, do professor (de Matemática), a partir de um forte entorno teórico cognitivista e que concede uma perspectiva sui generis para objetivar os modelos (e os esquemas de ação) de aprendizagem do trabalhador, mediante a execução de tarefas/atividades laborais exigidas no interior de situações profissionais fundamentais (para o respectivo métier). (MAYEN, 2012).

Isso posto, com um escopo de maior precisão para o desenvolvimento das demais seções, iniciaremos, agora, a indicação de alguns pressupostos iniciais assumidos pela (DP), mediante a descrição de sua identidade como um campo de investigação e pesquisa. Logo em seguida, abordaremos alguns elementos que podem concorrer para um trato sistemático e para a pesquisa necessária em torno da noção de competência profissional, com forte teor de interesse manifesto pela (DP), inclusive a partir do funcionamento e a determinação dos conceitos pragmáticos.

Dessa forma, assinalaremos uma preocupação semelhante de teóricos da (DM) e da (DP), com o escopo de explicar o papel da noção de "situação profissional" e o processo de competência profissional como uma capacidade plástica e adaptativa diante de um conjunto de situações profissionais fundamentais (no trabalho) e que concorrem para a consubstanciação, pela primeira vez na literatura, do termo que denominaremos por Situação Didática Profissional (SDP), bem como a noção de obstáculos profissionais, a noção de transposição profissional, a noção de contágio profissional e do contrato profissional ou contrato de ensino.

Por fim, indicaremos, de forma preliminar, um itinerário necessário para a discussão teórica do uso, em caráter de complementaridade teórica, dos pressupostos da (DP) e da (DM), mediante o desenvolvimento de Engenharias de Formação (de $2^{\mathrm{a}}$ geração) no Brasil.

\section{Didática Profissional (DP): origem e alguns pressupostos}

Pastré (1999) acentuou que o problema da competência profissional envolve uma discussão multidisciplinar que, a despeito da existência de vários tipos de abordagens ou expedientes de análise desenvolvidos por vários especialistas (psicólogos do trabalho, sociólogos, didatas, economistas, etc), podemos identificar três níveis representativos. O primeiro nível envolve compreender as modificações e as transformações que afetam o trabalho e as novas competências exigidas. O segundo nível, envolve o campo social e político e, por fim, o terceiro nível, diz respeito ao desenvolvimento cognitivo pessoal do trabalhador, isto é, 
como se constroem, se combinam e se reconstroem as competências (habilidades laborais) de um trabalhador, ao longo de sua trajetória de vida no trabalho. No excerto abaixo, apesar de extenso, se mostra imprescidínvel para que possamos compreender o entorno teórico que afetou a corrente francesa de estudos da (DP). Nesse sentido, Pastré, Mayen e Vergnaud (2006) explicam:

La didactique professionnelle est née au confluent d'un champ de pratiques, la formation des adultes, et de trois courants théoriques, la psychologie du développement, l'ergonomie cognitive et la didactique. On peut dire qu'elle a pris corps autour de trois orientations. Première orientation: l'analyse des apprentissages ne peut pas être séparée de l'analyse de l'activité des acteurs. Si on prend au sérieux une perspective de développement, il faut reconnaître une continuité profonde entre agir et apprendre de et dans son activité. D'où, deuxième orientation, si on veut pouvoir analyser la formation des compétences professionnelles, il faut aller les observer d'abord, non pas dans les écoles, mais sur les lieux de travail. Enfin, troisième orientation, pour comprendre comment s'articulent activité et apprentissage dans un contexte de travail, il vaut la peine de mobiliser la théorie de la conceptualisation dans l'action, qui, issue de Piaget et reprise par Vergnaud, utilisant les concepts de schème et d'invariant opératoire, permet de comprendre comment peut se développer une intelligence de l'action. Ajoutons que la didactique professionnelle se veut pleinement une didactique, c'est-à-dire une étude des processus de transmission et d'appropriation des connaissances en ce qu'elles ont de spécifique par rapports aux contenus à apprendre. Simplement, elle se centre beaucoup plus sur l'activité que sur les savoirs. (PASTRÉ, MAYEN e VERGNAUD, 2006, p. 165)

Pastré, Mayen e Vergnaud (2006) comentam que, no início dos anos 90, um grupo de especialistas franceses, originados de um campo de prática na formação de adultos e o desenvolvimento de Engenharias de Formação (EF) se constitui para a criação da (DP). Inicialmente, a partir dos três campos ou orientações de interesse para a (DP), podemos compreender e ainda identificar a influência dos fundamentos da Psicologia Ergonômica, proporcionando uma fina apreciação e distinção entre "tarefa prescrita" e "atividade". Por sua vez, Pastré, Mayen e Vergnaud (2006) assinalam ainda a influência da Ergonomia da língua francesa e, por fim, alguns elementos da Psicologia Russa do Trabalho.

Pastré (2002) explica que em sua primeira etapa de desenvolvimento, a formação profissional contínua foi colocada em evidência no campo da (DP) e, do ponto de vista prático e teórico, se observou a introdução e o emprego expressivo na França de uma abrangente de 
Engenharia de Formação (EF) ou Engenharia Pedagógica (EP), ao decurso dos anos 60 (BOTERF, 1999; HERBRARD, 2011; LECLERCQ, 2002).

Nesse contexto, a Psicologia do trabalho certamente trouxe para a (DP) um conjunto de técnicas e métodos em análise do trabalho, mas, ainda, proporcionou uma apreciação da dimensão cognitiva das atividades profissionais. E, visando uma compreensão das principais fontes de influência, recordamos os trabalhos clássicos de Faverge (1955), Leplat (1985, 2003; 2004; 2006; 2008) e Savoyant (1979). Pastré (2002; 2007b. 2017) explica que, historicamente, esse grupo de especialistas proporcionou uma perspectiva preliminar e diferenciada para a interpretação do binômio tarefa-atividade, mediante um viés qualitativo da atividade.

A corrente da conceptualização da ação se constitui, também, como um outro aporte teórico representativo para a (DP). Nesse caso, o ponto de partida foi constituído pela interpretação do binômio situação-atividade, com origem no pensamento de Vergnaud (1985), como uma espécie de prolongamento natural do pensamento piagetiano a respeito da conceptualização da ação. No trecho seguinte, Pastré (2002) explica a incorporação do pensamento de Vergnaud (1985) ao campo de pressupostos considerados pela (DP), a partir da constatação de que determinadas noções oriundas da Psicologia do Trabalho requeriam outras interpretações atinentes ao fenômeno do desenvolvimento profissional.

Ici nous quittons l'analyse du travail pour revenir à la psychologie du développement, la particularité de Vergnaud étant de lier ensemble approche développementale et analyse didactique. Je peux dire que mon propre travail théorique en didactique professionnelle a été de chercher à savoir si le cadre théorique développé par Vergnaud pouvait s'appliquer à l'analyse des situations de travail, en vue d'expliquer comment se construisent et se développent les compétences professionnelles. Ce cadre théorique s'est construit autour des concepts de schème et d'invariant opératoire, concepts empruntés à Piaget, mais réinterprétés dans le cadre d'une théorie des situations. Au fond, les apports de la psychologie du travail que j'ai mentionnés avaient le mérite d'insister sur la dimension cognitive du travail, mais sans préciser suffisamment en quoi consistait cette cognition. (PASTRÉ, 2002, p. 11)

Pastré, Mayen e Vergnaud (2006) acrescentam uma perspectiva adotada que envolveu uma espécie de "viés de complementaridade", diante da adoção de três orientações e que representam os autênticos interesses investigativos para a (DP), como podemos ver a seguir:

En résumé, la psychologie ergonomique a constitué un appui considérable pour la didactique professionnelle: d'une part elle a fourni des méthodes pour mettre en place une analyse du travail orientée « 
formation et développement des compétences professionnelles ». D'autre part, en mettant l'accent sur l'importance de la conceptualisation dans l'activité de travail, elle a permis d'établir un point avec la principale source théorique de la didactique professionnelle: la psychologie du développement, notamment le courant de la conceptualisation dans l'action. (PASTRÉ, MAYEN e VERGNAUD, 2006).

Não obstante, para que possamos compreender a constituição do campo de estudos da (DP) que, como mencionamos anteriormente, ocorreu na França no início dos anos 90, urge considerarmos um cenário de influência das mudanças na Europa das relações de trabalho pósguerra (HEBRARD, 2011). De fato, durante este emblemático momento histórico, divisamos uma perspectiva tayloriana sobre o trabalho, evidenciando-se pela noção de competência e que se resumia à capacidade de execução prescrita de tarefas, sobretudo, com uma atenção maior endereçada para o sujeito (trabalhador) individual (SAVOYANT, 1996). Mas, diante de um processo de evolução e automatização das ações, o caráter coletivo do trabalho se mostrou em evidência, com a migração gradual do individual para o coletivo, o que marcou os interesses de estudos psicossociais. (SAVOYANT, 1974, p. 220) e correspondente, um viés acentuadamente qualitativo para sua análise.

Pastré (2004, p. 215) assinala que, durante o período da crise da organização do trabalho, na perpectiva tayloriana, a noção de competência profissional enlargueçeu progressivamente seu próprio significado, diante de um cenário de crescente complexidade dos processos requeridos no campo do trabalho (SAVOYANT, 1974, p. 219). Mediante um movimento de mudanças, "outras formas inusitadas de trabalho colocam os operadores diante da tarefa de resolução de problemas" (PASTRÉ, 2004, p. 215). Observou-se uma mudança gradativa de foco no individual para o coletivo, no trabalho, com preocupação substancial com os processos fundamentais de transmissão, de veiculação estratégica das informações e da organização em grupo (SAVOYANT, 1974, p. 221).

Pastré (2004) acentua uma mudança de perspectiva e compreensão das relações laborais, na medida em que se passa a considerar um viés qualitativo de aplicação estratégica de procedimentos multidimensionais visando a resolução e o exame de problemas complexos, erráticos e não triviais no trabalho, como constatamos logo abaixo:

Et par voie de conséquence, une crise de la prescription du travail: quand on a affaire à un environnement dynamique, l'application des procédures ne suffit plus comme guide de l'activité. Il faut que les 
opérateurs soient capables de faire à tout moment un diagnostic de la situation, qui devient un élément central de la compétence. D'autres formes de travail mettent les opérateurs en situation de résolution de problèmes. Ce qui est intéressant, c'est que les problèmes à résoudre comportent des dimensions multiples; il faut alors trouver entre ces dimensions un compromis acceptable. On est dans ce qu'on pourrait appeler une intelligence stratégique de la situation, où il ne s'agit plus de trouver où est l'erreur, ou le dysfonctionnement, mais où il s'agit de construire une solution qui tienne compte des différentes dimensions du problème. (PASTRÉ, 2004, p. 4).

A (DP) proporciona objetivarmos o trabalho e o desenvolvimento profissional de um ponto de vista dialético, na medida em que não permite dissociarmos o conhecimento da ação e da situação (profissional). Desse modo, a corrente da conceptualização da ação, oriunda do pensamento de Piaget (1974), possibilitou a ampliação de uma perspectiva de análise, posto que "o conhecimento é fundamentalmente uma adaptação, a maneira pela qual os humanos são capazes de se ajustar ao seu meio" (PASTRÉ, 2011, p. 86). Por outro lado, a despeito de uma identidade teórica derivada de uma percepção aplicada de determinados fundamentos da Didática, urge uma demarcação e distinção, por exemplo, entre a (DP) e a Didática das Ciências (DC), esta última, por exemplo, originada e profundamente condicionada por um campo epistêmico disciplinar clássico (ALVES, 2017; 2019; 2020; JOSHUA e DUPIN, 1993). Nesse sentido, Pastré (2011) busca demarcar dois campos de interesse e de investigação específicos, quando observa a distinção dos interesses da (DP) e da (DC):

A l'inverse, le but premier de la didactique professionnelle fut de mettre en exergue la nécessité de faire une analyse du travail comme préalable à toute formation professionnelle, ce qui l'a amené à s'emparer des concepts et méthodes de la psychologie ergonomique. De la même manière, à son point de départ, la didactique professionnelle a tenu à marquer sa diférence avec les didactiques des disciplines: celles-ci sont structurées autour de la transmission et de l'acquisition de savoirs. La didactique professionnelle se centre sur l'apprentissage d'activités. Or, on le verra, le fait de prendre comme objet non un savoir, mais une activité entraîne des conséquences importantes. (PASTRÉ, 2011, p. 84)

Pastré (2011) acentua um itinerário de aperfeiçoamento gradual do aparato teórico considerado nesse campo de estudos. De forma inicial, constatamos uma forte recorrência à corrente da Psicologia do Trabalho, segundo a corrente francesa de estudos e a vertente russa. Não obstante, tendo em vista determinados fatores limitantes concernentes ao método clínico 
(CLOT e LEPLAT, 2004) recorrentemente empregado nos estudos ergonômicos (LEPLAT, 1985), registramos a seguinte mudança paulatina de interesse nos estudos da (DP).

Les premiers travaux de recherche de didactique professionnelle ont suivi scrupuleusement cette démarche: on cherchait à repérer les concepts organisateurs qui structurent la tâche, puis on regardait comment ces concepts étaient plus ou moins facilement et complètement mobilisés par les acteurs. Mais les limites de cette méthodologie sont peu à peu apparues. Le paradigme de Leplat est très bien adapté aux situations reposant sur une organisation taylorienne du travail: la tâche prescrite y est très détaillée et fournit un bon point de départ pour accéder à la tâche efective. (PASTRÉ, 2011, p. 86)

Decerto que a natureza dos dados produzidos por investigações desenvolvidas no continente europeu apresentou, ainda, uma outra variável indicadora de determinadas limitações. Com efeito, o próprio Pastré (2011) reconhece uma essência intrinsecamente complexa, derivada da necessidade de se compreender os mecanismos que ocorrem ao decurso (fluxo) de execução/realização de tarefas profissionais, posto que, as mesmas se mostram estruturadas recorrentemente por julgamentos, fatores circunstanciais e concepções pragmáticas que se aderem, organizam, corrigem e condicionam a atividade. Nesse sentido, Pastré (2011) constata os interesses da (DP) também endereçados aos fenômenos originados a partir de concepções pragmáticas (profissionais) e que adquiriu grande valor para a mesma.

Du coup, la démarche méthodologique est amenée à se complexiter: il faut certes toujours commencer par l'analyse de la tâche, mais celle-ci ne fournit guère qu'un squelette et est insui sante pour accéder de façon e à l'analyse de l'activité des agents. Pour cette dernière, on va chercher en didactique professionnelle à identifier, à côté des concepts qui structurent la tâche, des 'jugements pragmatiques', assez souvent implicites, qui permettent de comprendre comment les agents organisent leur activité. Autrement dit, la première démarche d'analyse du travail avait l'inconvénient d'être trop extrinsèque; la recherche et l'identification de jugements pragmatiques chez les acteurs permet d'accéder directement à l'organisation de l'activité, par conséquent de développer une analyse intrinsèque de l'activité. (PASTRÉ, 2011,p. 87)

Ademais, o exame minucioso das concepções pragmáticas que organizam a atividade pode ser compreendido a partir dos percursos evolutivos indicados por Tourmen (2014) proporcionando, assim, uma visão globalizante sobre todo um quadro evolutivo atual e de desenvolvimento da pesquisa europeia no âmbito da (DP), quando a mesma comenta: 
En nous appuyant sur une revue de littérature en didactique professionnelle, nous monterons qu'il existe aujourd'hui une évolution dans les usages de ce cadre en formation. Ainsi, nous dégagerons 1) l'existence d'un premier type d'usage de la didactique professionnelle, qui consiste à utiliser l'analyse du travail pour construire la formation, usage qui fut celui des fondateurs de l'approche. Puis, nous montrerons 2) l'émergence récente d'um second type d'usage qui consiste à former par l'analyse du travail. L'analyse du travail est en effet de plus en plus réalisée au cours de la formation (et non plus au préalable), ce qui nous amènera a revenir sur les origines et les implications de cette évolution. Nous monterons enfin 3) que si ces usages peuvent faire craindre un éclatement du cadre théorique et méthodologique de la didactique professionnelle, ils trouvent au contraire leur unité dans la théorie des schèmes de Vergnaud (1996, 2001a), qui, en proposant quatre entrées pour concevoir et animer la formation, fournit un cadre pratique (et pas seulement théorique) au premier comme au second type d'usage de l'analyse du travail en formation. (TOURMEN, 2014, p. 12).

No bojo de interesse pela análise do trabalho, Pastré (2002, p. 12) explica que os conceitos pragmáticos (julgamentos pragmáticos) servem, principalmente, para a efetivação de um diagnóstico tácito das situações profissionais, tendo em vista à eficiência, sua organização e o cumprimento precípuo de objetivos e metas definidas. Em tese, o que se vislumbra nessa condição, não se revela pelo componente epistêmico clássico (disciplinar) ou formal de saberes científicos e técnicos, mas, pelo seu viés pragmático. Pastré (2002, p. 13) esclarece que "um diagnóstico de uma situação não pode se contentar ao aproximativo e globalizante. É necessário selecionar o que se apresenta na situação como realmente pertinente”. Neste cenário caberá, pois, a distinção entre os profissionais noviços (aprendizes) e os profissionais experientes (experts). Os profissionais experientes extraem poucas e necessárias informações sobre a situação e, muito frequentemente, se atêm a determinados detalhes estratégicamente essenciais e mais relevantes (FISCHBEIN, 1987, p. 60) que podem se mostrar relativizados e/ou negligenciados pelo profissional noviço (aprendiz).

Por outro lado, registramos uma tradição dos estudos em Psicologia do Trabalho, com o emprego do Método Clínico (CLOT e LEPLAT, 2004) e a identificação de obstáculos e/ou barreiras inerentes ao desenvolvimento de atividades laborais. Por exemplo, abaixo podemos confirmar e constatar a descrição do que denominamos por "obstáculos profissionais" oriundos da necessidade de execução de atividades no ambiente de trabalho, atuantes como "effets parasites" (efeitos parasitas). Nesse sentido, Clot e Leplat (2004) advertem que: 
L'activité conduit parfois à des effets non visés par le sujet: erreurs, incidents, accidents. Des effets non souhaités accompagnent aussi éventuellement des effets qui eux étaient bien visés. Ces effets parasites ont été souvent décrits en analyse du travail: par exemple, le conducteur a bien évité un obstacle, mais, ce faisant, il en a heurté un autre. La connaissance et l'analyse de ces effets indésirés sont particulièrement utiles pour l'analyse de l'activité quand ces effets ne sont pas seulement considérés sous l'angle négatif, mais comme des symptômes révélateurs des caractéristiques de l'activité. La méthode clinique a trouvé un champ privilégié d'application dans l'étude de ces effets non souhaités et les méthodes d'analyse du travail en offrent de nombreux exemples, même si ceux-ci ne font pas référence à la méthode clinique. (CLOT e LEPLAt, 2004, p. 298).

Do excerto acima, imediatamente, depreendemos um raciocínio comparativo e oriundo da noção de obstáculo epistemológico que, de modo sui generis, foi introduzido ao campo da (DM), a partir do ponto de vista propugnado por Brousseau (1986), mediante a noção de obstáculo epistemológico que, por sua vez foi derivado o pensamento de Barchelard (1934). Por outro lado, quando objetivamos a atividade profissional e, de modo particular, a atividade profissional do professor de Matemática, urge uma compreensão semelhante da noção de uma espécie de entrave inescapável e resiliente do que denominamos por "obstáculo profissional", como uma condição ou uma barreira definidora, em muitos casos, da distinção social e denominação pragmática entre um profissional (professor) debutante e um profissional (professor) experiente (expert).

Não podemos desconsiderar uma tradição e a influência expressiva dos estudos desenvolvidos no campo da Psicologia francesa, nos meados dos anos 80. Não por coincidência, depreendemos que o pensamento de Brousseau (1986) se mostra largamente afetado por esses estudos em Psicologia (com origem piagetiana) quando, por exemplo, coloca e indica um papel importante para a noção de "situação" e/ou a "análise das situações e da atividade", como método próprio em Psicologia e com o escopo de desenvolver um mecanismo preciso de coleta de dados. Nesse sentido, trazemos um fragmento do pensamento de Leplat (1983) que corrobora com nossa última ilação.

L'analyse des situations s'est vu accorder une grande place dans certains secteurs de la psychologie; ainsin en est-il en psychologie du travail avec l'analyse du travail et ainsi en est-il dans tous le domaine où le psychologue prend pour point de départ de ses analyses des situations de l'a vie courante, non conçues par lui. L'analyse de ces situations pose des problèmes à la fois théorique et méthodologiques. Théoriques: 
puisque que la conception qu'on adopte pour l'activité orientera directement la démarche, suggérera les observables à recueillir et le type de mécanisme à mettre en lummière. Méthodologiques: pour definir le méthode propre à obternir ces observables et à apporter toutes les informations utile à l'élaboration du modèle de la situation. (LEPLAT, 1983, p. 50)

Cabe uma pequena digressão, no sentido de proporcionar uma depuração e clara distinção dos significados e terminologias recorrentemente mobilizadas até aqui. Tal expediente costuma ser indicado e respeitado no contexto da (DM), quando observamos a distinção entre saber (savoir) e conhecimento (connaissance), inclusive, seu emprego no cenário de investigação em Didatica da Matemática (MARGOLINAS, 2014). Nesse sentido, Brousseau assinala a distinção entre o saber (savoir) como elemento constitutivo de um patrimônio cultural e, o conhecimento (connaissance) como um repertório construído e elaborado, de modo particular, por um grupo de sujeitos (estudantes). Semelhantemente, no campo da (DP) e, ainda, segundo a tradição da corrente do Trabalho francês, urge distinguir os termos: activité, tâche, travail, emploi, poste de travail, métier, profession. Segundo os estudos ergonômicos, a activité (atividade) se constitui como o trabalho ao decurso de sua realização e a sua duração, acompanhada irremediávelmente de sua execução efetiva, por imtermédio do emprego de regras e a formação correspondente de uma representação mental derivada da ação ou atividade.

Mas, a tarefa (tâche) se constitui como "um conjunto de objetivos e procedimentos prescritos, diante de performances exigidas e da qualidade esperada" (TOURMEN, 2007, p. 516). Por outro lado, determinadas tarefas ou funções de trabalho são definidas e demarcadas pela própria estrutura hierárquica institucional escolar e, "alguns indivíduos são recrutados, diante de suas competências e qualificações" (TOURMEN, 2007, p. 517). Assim, a noção de poste de travail (posto de trabalho) possui uma função definida e situada, segundo os interesses organizacionais (institucionais) declarados no trabalho e que congrega ou reune profissionais (ou professores), cujas funções são idênticas ou semelhantes, no que concerne ao conjunto de tarefas determinadas por uma instituição (de ensino).

Vejamos, agora, a noção de métier que se distingue da noção de profission, segundo a língua francesa. Com efeito, Tourmen (2007) comenta que a noção de métier "se mostra mais complexa, do que parece, à primeira vista" e, a despeito de seu uso corrente, se evidencia um entendimento persistentemente confuso sobre o mesmo. Alguns autores da corrente do trabalho definem a profissão (profission) como determinadas formas de organização histórica e social. 
Assim, podemos divisar quatro elementos fundamentais: organização profissional, identidade profissional, evolução do trabalho e conjunto de saberes específicos.

Assim, o métier se origina, quando se observa pessoas, de um mesmo domínio de atuação, "que se reúnem para negociar a definição do papel, das tarefas, dos conhecimentos da prática, os conhecimentos especializados ao próprio posto devem desenvolver-se, com o objetivo de abandonar a polivalência indiferenciada" (TOURMEN, 2007, p. 518). Tourmen (2007, p. 519) esclarece um princípio básico para a identificação do métier, na medida em que "a partir do momento em que os atores ocupam certos postos de trabalho e se reagrupam para definir e defender, debater e estabilizar os conhecimentos da prática (savoir-faire) específica, reivindicando uma progressão ou identidade distinguida, podemos falar de métier". Sendo assim, quando falamos sobre a noção de métier, consideramos um sentido de uma estabilização e demarcação social imprescindível de uma esfera de práticas laborais ou um cenário das atividades profissionais especializadas, reunindo um grupo de profissionais.

Finalmente, chegamos ao termo "profission". Tourmen (2007) assinala que "uma abordagem sociológica norte-americana das profissões, originada em 1940 e vinculada à legislação americana distingue uma organização e associação profissional e instaura a distinção entre os termos profession e métier (ocuppation)". Assim, é mister que "a profissão seja socialmente necessária, e seu membros sigam um código deontológico, respeitado pelo grupo" (TOURMEN, 2007, p. 519). A partir desse entendimento, registramos a existência de uma espécie de "contrato profisssional" (no caso do professor, contrato de ensino), geralmente não explicito, e que possui a função de agrupar, legitimar e regular os indivíduos de um mesmo posto de trabalho, bem como, uma função de engendrar uma identidade (do oficio).

Para finalizar a presente seção, cabe registrar o interesse de Pastré (2002) no sentido de justificar a necessidade da adoção de não apenas os quadros de referência da Psicologia do Trabalho da vertente francesa e, adotar, paulatinamente, o quadro teórico desenvolvido por Vergnaud (2007). Nesse sentido, Pastré (2002) assinala o caráter de imprescindibilidade de explicar como se desenvolvem e se constroem as competências profissionais, por intermédio de um entendimento da atividade de adaptação do sujeito. Apesar de que a dimensão cognitiva do trabalho se mostra um objeto de investigação imprescindivel para a Psicologia do Trabalho, entretanto, notamos que "a mesma não precise, de forma clara, em que consiste tal cognição" (PASTRÉ, 2002, p. 11)). 
Constataremos, nas seções subsequentes, que a cognição para Vergnaud se transforma na conceptualização na ação, com forte herança piagetiana. E, assim, a (DP) considera uma ideia relativamente prosaica: para a análise das competências, se torna necessário analisar o caráter de eficacidade das ações e suas formas de organização, mediante a identificação de entidades ontológicas organizacionais (esquemas cognitivos e invariantes operatórios) da ação do sujeito em atividade laboral. Por conseguinte, "analisar as competências se torna uma análise da organização da ação" (PASTRÉ, 2002, p. 11), diante da identificação de elementos que correspondem pela sua invariância, ajuste e pela sua regularidade. Com origem nessa perspectiva, logo em seguida, abordaremos duas noções centrais para a (DP), a saber: a noção de competência profissional e o papel das concepções pragmáticas.

\section{Didática Profissional (DP): sobre a noção de competência profissional e os conceitos pragmáticos}

Na seção anterior abordamos, não de modo exaustivo, alguns conceitos e um itinerário constitutivo, histórico e evolutivo para a (DP). Doravante, buscaremos constituir um percurso capaz de auxiliar a compreensão da emblemática noção de competência profissional e, a partir disto, ensejaremos apresentar um conjunto de elementos característicos e vinculados com a noção de competência profissional do professor de Matemática. Nossa preocupação se respalda pelo fato de que, nos estudos da (DM), podemos registrar uma crítica endereçada precisamente ao componente teórico pouco preciso e/ou desenvolvido e indiferenciado em torno do papel e da atividade do professor (MARGOLINAS, 2004).

Por outro lado, Pastré, Mayen e Vergnaud (2006) manifestam seu interesse pelo desenvolvimento profissional dos adultos e, acrescentam a contribuição e o avanço expressivo proveniente de alguns especialistas franceses da (DM) (Brousseau, Douady, Chevallard, etc), como divisamos abaixo no trecho.

Les adultes se développent au cours de leur expérience professionnelle, et au cours des formations initiales et continues qu'ils reçoivent. Il est naturel de se tourner vers les deux grands psychologues du développement que sont Piaget et Vygotski, pour puiser dans leur travail les inspirations susceptibles de nourrir le cadre théorique et méthodologique de la didactique professionnelle. Il se trouve que tous deux ont mis en avant les idées d'activité et de conceptualisation, qui sont justement essentielles pour la didactique professionnelle. Cela n'est pas suffisant, et il faut faire appel en même temps à d'autres auteurs, comme Bachelard en philosophie des sciences et comme Brousseau, 
Douady ou Chevallard, en didactique des mathématiques. (PASTRÉ, MAYEN e VERGNAUD, 2006)

Pastré (2004) explica um movimento dialético entre os fenômenos que concorrem para a aprendizagem de conhecimentos e, progressivamente, a automatização das ações de um indivíduo (trabalhador ou professor), a evolução dos sistemas (e esquemas cognitivos) e o ajuste ergonômico próprio do individuo que concorre para revelar a sua capacidade (nem sempre consciente) e a sua competência profissional, como observamos abaixo.

Mais une fois l'apprentissage effectué, la compétence n'a plus besoin de l'activité de la conscience, sauf quand survient un imprévu. Là encore on ne peut pas comprendre ce qu'est une compétence en dehors de son rapport au corps propre. Ainsi, contrairement aux connaissances, dont on peut penser qu'elles s'accompagnent toujours de conscience quand elles sont évoquées, les compétences peuvent être mobilisées soit de façon consciente, soit le plus souvent de façon non consciente, sous forme de compétences incorporées. Ce mouvement d'automatisation des compétences après apprentissage est d'une grande importance pratique, car il permet de déplacer la vigilance du sujet vers des niveaux supérieurs de l'activité, plus complexes et plus intégrés. (PASTRÉ, 2004, p. 7)

A adoção de fortes pressupostos derivados da teoria da conceptualização da ação, com origem histórica no pensamento de Vergnaud (2001; 2007a; 2007b), revela a evidente atenção dedicada por Pastré (2004) para as noções de "situação", "tarefa", "atividade", "representações mentais", "esquemas cognitivos", como princípios reguladores e adaptativos para a atividade. Assumimos, pois, a perspectiva de Vergnaud (2007), no sentido de interpretar as representações mentais como um conjunto de esquemas, com função precípua de organizar e orientar a ação e a capacidade de simulação do real. De modo afetado pela teoria de Vergnaud, Pastré (2002) manifesta o seguinte ponto de vista à respeito da noção de campo profissional:

On retrouve là le couple situation-activité tel qu'on l'a analysé chez Vergnaud: il faut identifier les dimensions caractéristiques de la situation dans sa spécificité pour comprendre comment les sujets organisent leur action, par une conceptualisation plus ou moins profonde. Ainsi on pourrait dire que les concepts pragmatiques sont présents de deux manières: ils sont présents dans la situation, non pas à titre de concepts, mais à titre de dimensions pertinentes du réel, qu'il s'avère indispensable de prendre en compte pour avoir une action efficace. Ils sont présents dans la représentation des acteurs (quand ceux-ci ont opéré une conceptualisation adéquate) comme principes d'organisation de l'action efficace. Un concept pragmatique devient ainsi 
représentatif d'un champ professionnel, mais aussi d'un type de stratégie qu'un acteur est capable de mobiliser. (PASTRÉ, 2002, p. 13).

Cabe observar que Vergnaud (2007) confirma alguns argumentos explicitados por Pastré (2002). Logo em seguida, Vergnaud (2007) revela o real teor e a natureza da noção de competência profissional. Sua descrição se apresenta irremediavelmente vinculada e condicionada pela noção de capacidade plástica adaptativa do indívíduo (trabalhador ou professor), diante de um conjunto de situações (profissionais) características e fundamentais para o exercício efetivo de um determinado métier e que conferem, de modo irremediável, um componente pragmático atinente à noção de "competência profissional em situação".

Le concept de compétence n'est pas pour moi un concept scientifique, c'est un concept pragmatique, pratique, qui sert et dont je me sers constamment car je fais partie d'une communauté humaine dans laquelle on a besoin de communiquer, y compris avec des termes non systématiquement savants. Je vais tout de même parler des concepts savants, comme les schèmes, les invariants opératoires, les concepts-enacte, les théorèmes-en-acte, car, pour des formateurs d'enseignants, ce sont des concepts essentiels. J'ai besoin, si je veux être opérationnel, de regarder les compétences en situation et en particulier dans des classes de situations. En effet, on n'est pas compétent pour une situation singulière, mais, en général pour des situations qui appartiennent à une certaine classe, qui ont certaines caractéristiques. On a besoin d'analyser l'activité dans ses rapports avec les caractéristiques des situations. (VERGNAUD, 2007, p. 1).

Pastré (2011), por sua vez, acrescenta um viés de relativização, em consonância com a capacidade profissional, a depender do caso de um profissional (expert) experiente e um outro profissional (iniciante) inexperiente no métier (o noviço). Nesse sentido, Pastré (2011) apresenta um ponto de vista de relativização do problema e diferentes níveis de sua manifestação, quando declara e confere a importância da complexidade dos problemas, ao mencionar que:

La complexité d'un problème est indépendante du niveau de compétence atteint par l'acteur: elle vaut aussi bien pour un expert que pour un novice. La dificulté du problème est relative au sujet qui le rencontre: ce qui n'est plus un problème pour un professionnel peut être un problème d'une grande dificulté pour un novice (PASTRÉ, 2011, p. 91)

Como indicamos há pouco, o papel imprescindível do funcionamento dos conceitos pragmáticos permeia um forte componente das relações laborais estabelecidas entre os sujeitos. No caso da Psicologia do Trabalho, podemos extrair várias repercussões para viuslumbrarmos 
a atividade e a competência do professor de Matemática. De fato, no excerto que segue, podemos registrar um conjunto de regras deondônticas, partilhadas pelos sujeitos (trabalhadores) que coabitam um determinado posto de trabalho (poste de travail). Observamos, entretanto, que existe um componente cognitivo capaz de explicar o reconhecimento de uma espécie de "contrato profissional" que, embora não disposto de forma oficial ou normativa, por intermédio de textos normativos ou diretivas, tais regras (implícitas) concorrem para a orientação e um princípio de estabilidade, de identidade e se constitui como um fator da competência profissional. Nesse caso, eventualmente, objetivado e compartilhado para todo um grupo e que confere sua identidade como um "gênero profissional" (genre profissionelle). Tal noção recebe a atenção de Clot e Leplat (2005), como apreciamos a seguir.

Les groupes de travail vivent et travaillent mieux lorsque existent des règles non écrites, non prescrites par l'organisation mais conçues par les acteurs, négociées entre eux et, selon les cas, avec les hiérarchies. Ce travail de réorganisation du travail par le collectif constitue une ressource psychologique majeure pour les opérateurs qui peuvent agir ainsi sur l'organisation officielle du travail. [...] En un sens c'est là « le métier qui parle ", si l'on entend par métier non pas seulement les compétences techniques du sujet mais le « répondant » collectif qui se porte garant de l'activité individuelle. C'est ce dont le concept de genre professionnel vise à rendre compte: les manières de prendre les choses et les gens stabilisés au moins temporairement dans un milieu de travail donné. (CLOT e LEPLAT, 2005, p. 305 - 306)

Cabe registrar que "o conhecimento é considerado, certamente, como um objeto de conhecimento para o psicólogo cognitivo que investiga suas representações, mas, também como construção, através do processo de conceituação da própria atividade do sujeito" (MUNOZ, 2007, p. 40). Por conseguinte, qualquer análise ou pretensão de avaliação da competência profissional não poderá ser apartada do entendimento do intrínseco processo de elaboração de representações mentais do sujeito, quer se trate de uma criança ou de um adulto. Ademais, o caráter dinâmico das representações mentais preserva sua essência fortemente derivada e condicionada pela a ação e, em nosso caso de interesse, pela execução de tarefas profissionais. (LEPLAT, 2002; OLRY, 2009; 2012), não obstante, por vezes, a mesma pode ser afetada pelo estilo e funcionamento lacônico dos experts (PASTRÉ, 2001, p. 6).

Por conseguinte, além de relativizarmos o caráter peculiar de "problemas parasitas" e recorrentes em qualquer atividade especializada, não podemos perder de vista o caráter objetivado e identificável da ação e atividade desenvolvida, uma vez que "a ação é sempre a 
primeira. O conhecimento não se apresenta ou se manifesta por saber dizer ou escrever algum texto, o mesmo se configura por agir e, em situação" (VERGNAUD, 2007, p. 3).

No trecho que segue trazemos um exemplo clássico discutido por Perrin-Glorian (1993). O evento evidenciado diz respeito a uma situação fundamental típica e que coloca em destaque a capacidade profissional e, portanto, a competência do professor de Matemática em regular os elementos oriundos da avaliação e a evolução das aprendizagens de sua classe. Registramos dois critérios para a avaliação do sucesso do professor, na medida em que Perrin-Glorian (1993) aponta um plano institucional (avaliação oficial) e, um segundo critério situado e cirscunstanciado pelo andamento dos trabalhos no interior da sala de aula, consubstanciando, dessa forma, um índice qualitativo ou parâmetro de perceptual de sua competência.

La pression du côté de la réussite à court terme vient aussi bien des élèves et des parents que des collègues et semble plus forte au collège qu'à l'école élémentaire. Un minimum de réussite des élèves est nécessaire au professeur pour le fonctionnement de sa classe. C'est aussi le principal moyen de valorisation du professeur lui-même. La réussite du professeur peut s'évaluer sèlon deux critères: - d'une part, le succès des élèves aux examens ou aux contrôles, notamment s'ils sont communs à plusieurs classes du'même niveau (évaluation officielle). C'est d'ailleurs aussi ce qu'attendent les élèves et les parents d'élèves, d'autre part, la bonne marche de la classe, l'ambiance propice au travail, avec des élèves intéressés et qui prennent du "plaisir à faire des mathématiques. Un indice en est la participation des élèves. (PERRINGLORIAN, 1993, p. 25)

Indiscutivelmente, os elementos apontados acima por Perrin-Glorian (1993) que concorrem para um julgamento ou avaliação positiva do professor ultrapassam os limites de uma apreciação técnica ou do repertório de saberes científicos (disciplinares) disponíveis para um professor (de Matemática). Nesse sentido, reforçamos que "o conceito de competência é um conceito pragmático que nos permite comunicar, mesmo destituído de critérios de cientificidade, e que não nos permite um aprofundamento em detalhes do ponto de vista da análise da atividade". (VERGNAUD, 2007, p. 4). Vergnaud (2007) acentua um cenário indiferenciado de manifestação da noção de competência, quando esclarece que:

Mais le maître, comme l'enfant, développe ses compétences dans toute une série de registres: l'interaction avec autrui, la séduction, le défi, la communication et le langage. Ce n'est pas parce qu'on crée une situation de proportionnalité jugée opportune pour des élèves de quatrième qu'ils vont apprendre la proportionnalité seulement. Ils vont apprendre beaucoup d'autres choses. (VERGNAUD, 2007, p. 5) 
A partir de um modelo metafórico de automatização do trabalho, podemos compreender que, atualmente, a eficiência ou competência do professor se origina de uma capacidade, cada vez mais tácita e substancial de agir e reagir aos incidentes não previstos e situações (problemas) escolares inéditas. Por conseguinte, podemos adquirir um entendimento de que ser competente significa e se constitui por uma capacidade de gerenciar, cada vez mais, situações reconhecidamente complexas, situações erráticas e não triviais, todavia, recorrentes e invariantes no plano de um sistema escolar (ou instituição) e, de modo particularmente importante, no interior da sala de aula de Matemática. Por conseguinte, como explica Pastré (1999, p. 111), “a aplicação de bons procedimentos não se mostra suficiente e se torna premente saber adaptar os procedimentos aos comportamentos que se manifestam fora do normal".

Na seção seguinte buscaremos confirmar que a noção de situação profissional adquire valor distinguido para a (DP), todavia, vislumbrada como um cenário destituído de um interesse sistemático e observação (controle) da aprendizagem do individuo, a partir de um saber científico específico, como costumamos a verificar na (DM).

A partir deste cenário, poderemos delinear, um pouco mais adiante, determinados elementos que podem repercutir/convergir para a noção que nominamos por Situação Didática Profissional (SDP) que, como temos definido em nossos trabalhos (ALVES, 2018d, 2018e; 2018f; 2019; 2020), poderá ser descrita, de modo mnemônico, pela equação característica $\mathbf{S D P}=\mathbf{U T}+\mathbf{D P}$. Nessa equação característica definidora, uma Situação Didática Profissional (SDP) é consubstanciada como referência de uma determinada Unidade de Trabalho (UT) ${ }^{1}$ e a Didática Profissional (DP) corresponde a adoção e a impregnação dos fundamentos e dos pressupostos visando a demarcação epistêmica e/ou pragmática necessária para o seu controle em investigação e pesquisa.

\section{Didática Profissional (DP) e a noção de situação (didática) profisssional}

"Um conceito pragmático é característico de uma situação profissional [...] e específico a uma determinada classe de situações bastante limitadas" (PASTRÉ, 2002, p. 13). Com origem nesse pressuposto fundamental e em outras ilações, podemos depreender um lugar privilegiado

\footnotetext{
${ }^{1}$ Podemos exemplificar algumas unidades de trabalho na atividade do professor: (i) expediente de elaboração de provas; (ii) situações envolvendo a interação com os pais de estudantes; (iii) momento de comunicar a aprovação e reprovação de indivíduos; (iv) cumprimento de atividades da burocracia escolar; (v) realização de atendimentos individuais aos estudantes menos desenvolvidos, etc.
} 
e um raciocínio semelhante ao expediente de Brousseau (1986) ao caso da noção de situação didática. No contexto da (DP), se delineia um pensamento semelhante, na medida em que constatamos uma estrutura conceptual nuclear, intrinsecamente vinculada a um conjunto de situações profissionais caracteristicas, como apreciamos em seguida.

Pour chaque classe de situations professionnelles, il existe une structure conceptuelle, qu'on peut dégager par l'analyse cognitive de la tâche et qui est en quelque sorte le socle invariant qui va servir à organiser l'action efficace du sujet. Autrement dit, quand on veut analyser le travail d'un point de vue cognitif, les invariants qu'on va chercher ne correspondent plus à ce qu'on trouve chez Piaget avec le développement de l'enfant. Ce ne sont plus des invariants portant sur les propriétés des objets, comme les conservations piagétiennes, dont l'acquisition permet aux enfants de se construire une représentation du monde, qui correspond à une sorte de physique concrète (un objet possède une certaine masse, un poids, un volume, etc.). (PASTRÉ, 2004, p. 6).

Por outro lado, com o escopo de não desenvolvermos um ponto de vista restritivo sobre o contexto educacional francês de reformas educacionais, observamos as explicações de Altet (2010) a respeito do funcionamento e dos interesses dos Instituto Universitários de Formação de Mestres (Institut Universitaire de Formation des Maîtres - IUFM) e dos Insttutos de Pesquisa e Ensino de Matematica (Instituts de recherche sur l'enseignement des mathématiques - IREM) que, de modo recorrente, constatamos sua menção nos trabalhos da (DM) originados na França nos anos 80 e 90 (ARTIGUE, 1995, DOUADY, 1995, 1987), entretanto, com origem em um ponto de vista restrito ao caso da Matemática. Por sua vez, Prost (1999) discute um período de reformas na França, em um periodo histórico de 1960 e 1990. Menciona que a situação no início dos anos 60 preservou o dualismo do século XIX, com uma formação organizada pelas escolas normais (écoles normales) e condicionando, progressivamente, uma formação de professores abreviada (encurtada).

Um pouco mais adiante, Prost (1999, p. 21) comenta que mudanças políticas provocaram modificações no âmbito da formação de professores em amplo cenário educacional. Paulatinamente, "a pesquisa se desenvolveu nas Ciências da Educação, como vemos no caso da didática de determinadas disciplinas, notadamente em Matemática, graças aos IREM's". (PROST, 1999, p. 22). Não obstante, não podemos negligenciar um contexto ampliado de reformas que incidiram em um campo ampliado definidor do ofício e do trabalho do professor no sistema de ensino francês. Abaixo, divisamos uma preocupação dialética constante 
envolvendo os elementos de ordem teórica e de ordem prática como alicerce basilar para a formação geral de professores franceses estimulado pelos IREM's.

Avec la mise en place des IUFM (Institut Universitaire de Formation des Maîtres) en France en 1991, il s'est agi de repenser la formation dans le cadre du courant international de la professionnalisation, en particulier a partir de la création de nouveaux liens entre théorie et pratique. En France le terme de professionnalisation des enseignants, de l'activité enseignante, de la formation des enseignants, apparaît bien avec la création des IUFM, dans le rapport fondateur de D. Bancel (1989) qui défi nit la formation comme une élaboration conjointe de connaissances théoriques et pratiques des enseignants. (ALTET, 2010, p. 118)

Os elementos apontados acima inerentes às preocupações com o caráter de profissionalização de professores, de aperceiçoamento das atividades do ensino (conhecimentos teóricos e práticos) de disciplinas clássicas e específicas e que não podem ser objetivados por intermédio de um expediente que desconsidera o papel fundamental do funcionamento de uma "situação profissional" e que adquiriu um tratamento e perspectiva distinguida, por exemplo, a partir da teoria da conceptualização da ação.

Atualmente, Mayen (2012) preserva e produz um maior aprofundamento para a discussão em torno de situações profissionais (SP), isto é, situações típicas e recorrentes em determinado ofício (métier), entretanto, desprovidas de um caráter sistemático de observação, controle e entendimento dos processos engendrados para a aprendizagem do próprio trabalhador. Nesse sentido, podemos constatar um interesse relativamente atual da pesquisa em (DP), endereçada ao cenário e interesse da formação profissional, todavia, não condicionada ou estruturada por um viés disciplinar clássico, como costumamos constatar no campo da investigação em (DM) (ALVES, 2018e; 2018f; 2019; 2020). Adotando um ponto de vista originado no pensamento de Mayen (2012), podemos fazer referência a uma situação didática (prática) visando a constituição de conhecimentos (connaissance) originados da prática. Nesse sentido, o mesmo esclarece:

En didactique professionnelle, la notion de situation est d'abord définie comme fin: les situations, notamment professionnelles, sont a/ ce à quoi des professionnels ou futurs professionnels ont affaire, $b$ / ce avec quoi ils ont à faire (trouver le moyen de réaliser des tâches, de résoudre des difficultés de toutes natures...) au sens où ils doivent s'en accommoder et s'y accommoder. (Mayen, 2012, p. 62). 
No contexto da (DP), a análise do trabalho proporciona reconstituir os conhecimentos mobilizados ou elaborados em uma situação profissional (SP), todavia, não com uma sistemática necessária para sua apreciação e coleta de dados visando a pesquisa. Ademais, o interesse pelos conhecimentos que circulam, que se renovam e, bem como, outros conhecimentos profissionais que são colocados em desuso (se tornam obsoletos) ainda requerem uma maior síntese imprescindível de aprofundamento e pesquisa. Outrossim, de que modo podemos objetivar, de forma sistemática, o potencial de determinadas situações profissionais e, sobretudo, a transmissão profissional ou transposição sistemática (e pragmática) envolvendo, por ventura, os profissionais inexperientes e os mais experientes (experts) em situação?

Nesse sentido, propugnamos uma noção transposição profissional que, diferentemente da transposição didática (CHEVALLARD, 1991), que considera um movimento dialético clássico entre o saber científico (savoir savant) e o conhecimento matemático (savoir enseigné), desde o locus acadêmico até o contexto escolar, inclusive, o saber morto (savoir mort). Nesse caso, considaremos apenas os modelos de transmissão de conhecimentos originados na prática profissional (campo pragmático) e do exercício do ofício, com forte componente pragmático, circunstancial e não nessariamente epistêmico (disciplinar).

Podemos objetivar e compreender a noção ou um fenômeno de transposição profissional quando um professor inexperiente recebe um conjunto de tarefas indicadas/prescritas por um outro professor experiente (ou funcionário de uma instituição) e que envolvem, por exemplo, um processo de familiarização com os documentos oficiais prescritores, documentos normativos $^{2}$ e prescritores da atividade escolar, no caso de transposição profissional, objetivamos os fenômenos de transmissão de conhecimentos intrínsecos para o desenvolvimento de uma atividade profissional envolvendo, por exemplo, profissionais (professores) noviços e profissionais (professores) mais experientes.

De modo substancial, a "transposição profissional” ocorrerá em um cenário circunstanciado de situações típicas e fundamentais de trabalho ou, como chamamos até aqui,

\footnotetext{
2 "Os documentos normativos possuem um grande papel no trabalho, em todos os níveis, elementares e complexos, técnicos e organizacionais, de execução e concepção, da produção e da seguridade" (Leplat, 2004, p. 197). A necessidade de um documento normativo envolve, pelo menos em parte, um direcionamento de um conjunto de competências que atribui aos futuros utilizadores, bem como, suas necessidades e exigências. Se um profissional é julgado suficientemente competente para executar determinada tarefa, diante de todas as condições, sobretudo, condições adversas, então, os documentos normativos não se mostram de forma essencial e, apenas, uma função administrativa ou secundária.
} 
situações profissionais (SP), todavia, destituídas de uma visão de modelização teórica e interesse sistemático na formação do próprio professor e compreensão da aprendizagem. Enquanto que o binômio de relações identificado na transposição didática (CHEVALLARD, 1991) se constitui como professor - estudante, no caso de uma transposição profissional, assinalamos o (s) binômio (s) característicos e possíveis: "professor - professor (es)" ou "professor - instituição".

Mayen (2012) alerta sobre os seguintes aspectos atinentes a uma situação de trabalho e que, recorrentemente, são negligenciados no contexto de formação profissional inicial.

Penser les situations de travail a partir des perspectives ergonomiques et psychologiques permet de conserver une position a partir de laquelle la formation n'est pas inféodée aux exigences des situations professionnelles et à leurs exigences. L'analyse du travail pour la formation débouche dans bien des cas sur la mise en évidence des raisons pour lesquelles ce qui arrive dans cette situation ne relève pas (et parfois surtout pas) d'une perspective de formation. Comprendre suffisamment de choses aux situations de travail pour pouvoir parvenir à une telle conclusion constitue une raison déjà suffisante pour nous intéresser aux situations professionnelles. (MAYEN, 2012, p. 62).

Apesar da natureza intrínseca do trabalho, Mayen $(2012$, 62) enfatiza, como atividade condicionada a uma situação social imposta, decorrente de exigências e demandas. Aqui, encontramos a semelhança, por exemplo, com as situações escolares comuns, respeitando as especificidades de cada uma, podendo também estar sujeitas a certos obstáculos indicados no ensino da Ciências e Matemática, o que confirma a exigência constante de sua superação necessária, como a indicação sine qua non de um processo virtuoso de aprendizagem.

No caso anterior, segundo Mayen (2012), assumimos a noção de obstáculos aplicados ao campo das situações profissionais e, portanto, o distinguimos da noção de situação didática profissional (SDP), pois uma (SDP) é definida por um conjunto de interações envolvendo o aprendiz (profissional), o formador (de professores) e o conhecimento pragmático condicionado por uma unidade de trabalho (UT), ou seja, por uma situação característica e particular, recorrente e invariável, de uma atividade profissional. 


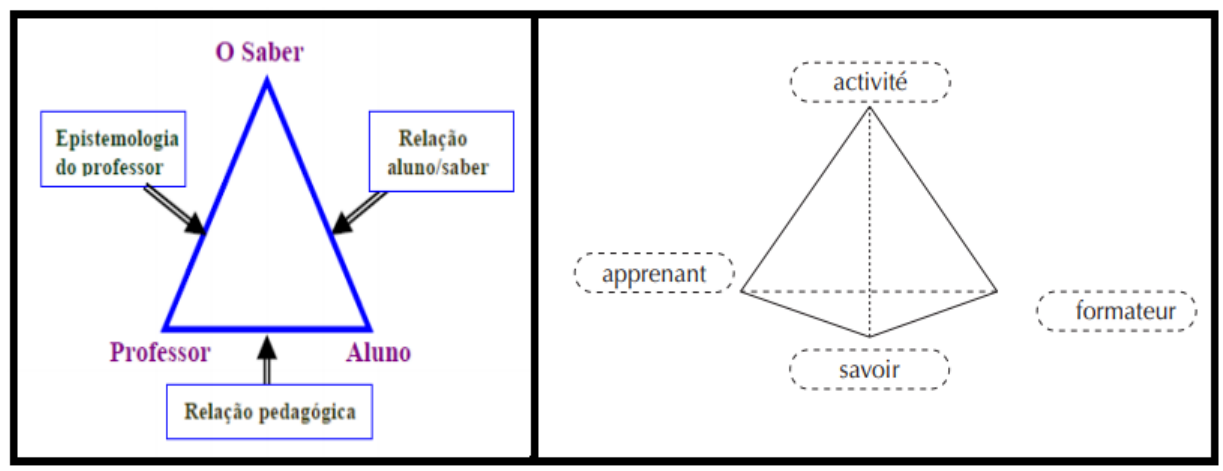

Figura 1. Triangulo clássico da Didática da Matemática (Brousseau, 1986) e, ao lado direito, o tetraedro que indica os elementos considerados nas relações investigadas pela DP (Baudouin, 1999).

$\mathrm{Na}$ figura acima, buscamos comparar o modelo pedagógico de análise inaugurada por Brousseau (1986a; 1986b), com atenção expressiva dedicada para a atividade do estudante. Por outro lado, quando assumimos os pressupostos da (DP), consideramos uma perspectiva concorde com Baudouin (1999) que insere uma figura tridimensional com o escopo de descrever novas relações emergentes. Na figura tetraédrica (3D), passamos a considerar os elementos constituintes de uma (SDP): atividade - saber - aprendente - formador.

Para nós, uma (SDP) possui uma função de capacitar o profisssiomal (o professor) de se prevenir, antever certos entraves, diante de situações profissionais (problemas complexos) que concorrem para o mal funcionamento do sistema (escolar) ou do próprio posto de trabalho (e da sala de aula), como podemos constatar nas palavras de Pastré (2011).

Considérons maintenant les problèmes complexes. Un acteur, avec un modèle opératoire très pertinent, entre en scène, cherche à obtenir une réponse à la situation présente désorganisée, quand il trouve une contradiction entre la réponse qui attend et celle qui observe. C'est généralement le cas lorsque l'acteur est confronté à une nouvelle classe de situations, par exemple un problème totalement nouveau, pour lequel son modèle opérationnel, pertinent pour les situations rencontrées dans le passé, est inadéquat pour le cas présent. Une telle occasion se présente comme très intéressante pour l'apprentissage. Le modèle opératoire de l'acteur n'est pas du tout disqualifié. Il est toujours valable de traiter de la classe des situations habituelles. Mais la situation exige d'agir, de se réorganiser pour pouvoir intégrer une nouvelle situation. On peut appeler cette extension du modèle opératoire de l'acteur, ce qui représente un approfondissement. (Pastré, 2011, p. 90)

Mayen (2012), por sua vez, explicita a necessidade da modelização de situações visando a construção de conbecimentos originados da atividade profissional, como divisamos: 
Nous pouvons aborder la notion de situation professionnelle en relation avec les savoirs. En didactique professionnelle, la formation ne part pas des savoirs scientifiques ou techniques, ni des procédures ou méthodes constituées, mais des situations professionnelles. Cette idée part du constat selon lequel une situation professionnelle - et c'est encore une voie pour avancer dans notre définition, n'est pas une situation disciplinaire, ni pluri ou multidisciplinaire. Elle est une unité à part entière, et l'activité n'y est ni application de procédures, de méthodes ou de techniques, ni application de savoirs. Une situation professionnelle n'est pas non plus une occurrence pratique d'un modèle théorique ni encore, une situation didactique (pratique) pour construire des savoirs. (Mayen, 2012, p. 66).

Aqui, cabe um expediente comparativo envolvendo a noção de situação profissional (SP) ou uma situação didática profissional (SDP), a partir de um expediente comparativo entre uma noção clássica derivada da (DM). No cenário de demarcação de noções clássicas e fundamentais para a (DM), podemos registar uma compreensão ou ponto de vista fortemente condicionado pelo campo epistêmico disciplinar (pelo saber científico matematico), como observamos na definição de "situação didática" fornecida por Brousseau (1986b).

La situation didactique est formée seulement de celles de ces relations qui sont spécifiques du «SAVOIR » visé et bien entendu de celles qui permettent de les définir. Il faut entendre par spécifiques les caractères et relations de ces deux sous-systèmes qui changeraient si le savoir visé changeait ou qui, étant changés, modifieraient le savoir acquis. (BROUSSEAU, 1986b. p. 54).

Brousseau (1986b) acentua o papel dos dois subsistemas (sistema educativo e o sistema de ensino). Esses dois sub-sistemas, conforme Brousseau, são vinculados e ligados a partir de condicionantes e relações recíprocas: "a situação didática propriamente dita” (BROUSSEAU, 1996b, p. 54). E, um pouco mais adiante, o mesmo acrescenta que "essa visão é bem diferente do ponto de vista usual de modelagem da situação sob a forma de uma situação de comunicação, sendo o transmissor o mestre, sendo o receptor o aluno e a mensagem sendo conhecimento" (BROUSSEAU, 1986b, p. 54). Constatamos aqui o modelo do trinômio clássico (ver figura 1, lado esquerdo) visando explicar os fenômenos derivados de uma situação didática. Por outro lado, recordamos a seguinte definição:

A situação adidática, como parte essencial da situação didática, é uma situação na qual a intenção de ensinar não é revelada ao aprendiz, mas foi imaginada, planejada e construída pelo 
professor para proporcionar a este as condições favoráveis para a apropriação do novo saber que deseja ensinar. (ALMOULOUD, 2007, p. 33).

A definição de "situação adidática" proporciona um princípio de modelização teórica comparativa imediata, na medida em que objetivamos um conjunto de situações profissionais, antevistas e exigidas por determinada instituição escolar e prescritas por um posto de trabalho, todavia, desprovida de um interesse, de per si, pela própria apreciação sistemática da capacidade de aprendizagem de um trabalhador (o professor). Parafraseando Almouloud (2007), em uma (SP), não se identifica a intenção de ensinar (comunicar) ao professor um "dicionário de normas e/ou tarefas" que precisam ser realizadas/executadas, a fim de garantir a estabilidade de funcionamento dos subsistemas escolares, bem como a estabilidade das relações funcionais dispostos em seus vários postos de trabalho. Por outro lado, quando passamos a tomar como referência o modelo tridimensional tetraédrico que vislumbramos na figura 1 (lado direito), iremos nos referir aos elementos básicos constituintes de uma (SDP). Nesse caso, uma preocupação explicita sobre o funcionamento dos esquemas (cognitivos) reguladores e ajuste da atividade e aprendizagem do professor de Matemática em situação são objetivados.

Concernentemente à aprendizagem do professor e que retrata nosso interesse, Pastré (2007, p. 83) comenta que a aprendizagem é uma atividade "que não consiste apenas em acumular conhecimentos e saberes, mas em configurar e reconfigurar os recursos cognitivos e, assim, transformar sua própria atividade para tornar melhor adaptada ao contexto e às situações”. Tal perspectiva, quando considerada a partir de um conhecimento disciplinar standard, como no caso o saber matemático, se coaduna ao entendimento de Pastré (2002), observando-se que, na teoria da conceptualização da ação endereçada ao caso da Matemática, ocorreu uma identificação clara do objeto matemático e em torno do qual se organiza e se antevê um conjunto de situações didáticas ou adidáticas. Pastré (2002) enaltece um movimento de análise completa na (DP), com a adoção do ponto de vista de Vergnaud, como depreendemos do trecho seguinte.

Mais Vergnaud, avec sa théorie des champs conceptuels, fournit le chaînon manquant pour adapter le cadre théorique de la conceptualisation dans l'action à la didactique professionnelle: une méthode pour analyser une classe de situations en identifiant les concepts à mobiliser pour résoudre les problèmes présents dans cette classe. (PASTRÉ, 2002, p. 12). 
Finalizamos a seção atual propugnando uma categorização e distinção entre: situação profissional (SP) e a nova noção introduzida agora e que denominamos por (SDP). Logo em seguida, buscaremos desenvolver o exame de determinados elementos que possuem um potencial de repercutir na pesquisa voltada para a compreensão da atividade do professor de matemática e detém um potencial organizacional para o desenvolvimento de pesquisa sistemática, visando o contexto de uma Engenharia Didática de Formação (EDF) (PERRINGLORIAN, 2011; TEMPIER, 2013) de repercussão no cenário brasileiro, mediante apenas a compreensão de determinados fenômenos (TEMPIER, 2013, p. 186).

\section{Didática Profissional (DP) e a repercussão para a pesquisa em torno da atividade e competência do professor de Matemática}

Com origem nas seções anteriores e diante da indicação de alguns dos pressupostos da (DP) assinalados, divisamos o seguinte questionamento: Quais contribuições a Didática Profissional (DP) pode proporcionar para a pesquisa em torno da prática dos professores de Matemática e o entendimento do processo evolutivo de sua competência profissional? Que quadros teóricos permitem perspectivar um aparato teórico conceptual e fenomenotecnológico, a fim de uma demarcação científica para área e pesquisa?

De modo preliminar, recordamos que Pastré (2007, p. 82) assume como hipótese de que, para toda atividade (laboral) profissional, inclusive a atividade do professor, divisamos a proficuidade da combinação ou um núcleo conceitual de "invariância" e de "variabilidade". Ademais, uma segunda hipótese importante assumida por Pastré (2007) diz respeito ao fato de que, o núcleo constitutivo da organização da ação (da atividade) é de caráter essencialmente conceptual. Por conseguinte, perspectivamos os indícios da constituição de uma identidade profissional e de uma competência profissional, na medida em um repertório de conhecimentos acumulados e constituídos pelo professor de Matemática configuram a invariância de suas ações, além de uma capacidade plástica e tácita de resposta diante de novos problemas que ocorrem no plano da sala de aula, no plano do posto de trabalho ou no interior de uma determinada instituição escolar ou agência governamental.

A categorização fornecida por Pastré (2007) indica uma clara relevância para os fenômenos de conceptualização das ações, quando declara que:

Nous supposons que le noyau central de cette organisation est de nature conceptuelle. Mais là il faut ajouter deux précisions: on parle de conceptualisation, et non pas de concepts ou 
de savoirs. On reste donc dans une approche centrée sur l'activité, avec l'idée que l'organisateur principal de l'activité réside dans un couplage entre un sujet et une situation Le sujet retient de la situation les dimensions qui vont orienter son action: c'est en ce sens qu'il conceptualise la situation. Par ailleurs, il s'agit bien du noyau central de l'organisation de l'activité, ce qui n'exclut pas l'existence d'autres organisateurs, notamment d'origine psychosociale. (PASTRÉ, 2007, p. 82)

Por conseguinte, se constitui um elemento fundamental para a pesquisa considerar, como elementos modelizadores, o binômio sujeito-atividade. A compreensão dos elementos organizadores de sua atividade devem receber maior atenção. De modo recorrente e cada vez com maior ênfase, Pastré (2007) assinala e se apoia em distinções clássicas inseridas no campo da (DM) a partir do pensamento de Brousseau (1986). Logo em seguida, divisamos dois processos basilares para a (DP), nominados por de "epistemização" e "pragmatização". Tais processos requerem um trato pormenorizado, visando uma repercussão adequada para a pesquisa. Pastré (2007) incorpora, de forma clara, vários fundamentos indicados por Brousseau (1998), quando observa que:

Je reprends ici une distinction utilisée par des didacticiens (Brousseau, 1998): le savoir est un ensemble d'énoncés portant sur um domaine, énoncés non contradictoires et reconnus valides par une communauté scientifique ou professionnelle; le savoir a une dimension objective. Les connaissances représentent toutes les ressources cognitives, d'ordre scientifique, empirique, etc., dont dispose un sujet: elles ont une dimension subjective. (PASTRÉ, 2007, p. 82)

Assim como Brousseau (1986) ou Vergnaud (1988), com forte impregnação do campo de estudos em Psicologia e influência piagetiana, os fenômenos decorrentes da aprendizagem são revelados com origem da atividade do estudante em situação. E, por intermédio de um modelo semelhante, ou, um principio de complementaridade envolvendo a (DP) e a (DM) (ALVES, 2018e; 2018f; 2019; 2020) que encetamos aqui, os fenômenos decorrentes da aprendizagem do professor de Matematica são decorrentes de sua atividade, de sua execução de tarefas, que correspondem a três planos específicos que se inserem em seu campo profissional, a saber: plano da sala de aula, plano do posto de trabalho e no plano da sua instituição escolar, inserida em um sistema educativo. Pastré (2007) proporciona uma compreensão pormemorizada da atividade de conceptualização específica do professor, quando observa adiante que: 
L'apprentissage est une activité de conceptualisation. Mais ici il faut bien faire la différence entre concept et conceptualisation. La conceptualisation est une activité; c'est certes une activité particulière, car elle est presque entièrement interne et invisible. Elle ne s'exprime que par son résultat: savoir résoudre des problèmes et savoir justifier le résultat obtenu. C'est ce côté interne de la conceptualisation qui rend tellement difficile l'analyse de l'activité enseignante. Car l'activité d'un enseignant a pour but de transformer une autre activité (celle des élèves), c'est-à-dire la manière dont les élèves conceptualisent une situation, manière qui n'est accessible que par indices. Le concept est le résultat final de cette activité de conceptualisation et on peut penser qu'il conserve toujours la trace du processus qui a permis de le construire. Donc en toute rigueur de termes, un concept ne se transmet pas, il est construit par un sujet. On peut transmettre des représentations, des savoirs; on ne peut pas transmettre des concepts: les concepts ne peuvent être que le résultat d'une activité de conceptualisation. Ce fut l'intuition de Piaget: la dimension constructiviste de l'apprentissage. (PASTRÉ, 2007, p. 84)

Propugnamos que a pesquisa em torno da atividade do professor de Matemática não pode prescindir de um "dicionário básico" a respeito da noção de competência profissional, mesmo que de ordem preliminarmente reducionista e que confere um viés preliminar de insuficiência, tendo em vista a ampla natureza instrinseca da noção de competência. Nesse sentido, empregamos o pensamento de Vergnaud (2001), ao explicar que "vou começar com várias definições complementares da habilidade e tentar convencê-lo de que a competência não é um conceito suficiente, mas que exige ao contrário dos desenvolvimentos importantes do lado da análise de atividade e processos cognitivos" (VERGNAUD, 2001, p. 2). E, em nosso caso de interesse, iremos modificar/alterar a proposta preliminar de Vergnaud (2001) e consideraremos, de modo hipotético, dois professores de Matemática A e B e, correspondentemente aos mesmos, descreveremos a noção de competência. Vejamos, de imediato, um conjunto de quatro definições (adaptadas) fornecidas a seguir.

Definição 1: O professor A é mais competente do que B se o mesmo consegue executar tarefas que B não sabe. A é mais competente do que $\mathrm{B}$, em um certo tempo ' $\mathrm{t}$ ', se o mesmo consegue realizar a mesma tarefa em um tempo ' $t$ ' e que $B$ não consegue.

Definição 2: O sujeito A é mais competente do que o sujeito B, se o mesmo consegue realizar de uma forma melhor. A "melhor" comparação assume critérios adicionais: velocidade, confiabilidade, economia, elegância, compatibilidade com a forma como os outros operam, etc ... (Vergnaud, 2012, p. 288). 
Definição 3: O professor A é mais competente do que o professor B se o mesmo dispõe de um repertório de recursos mais ampliados do que B. De modo geral, para lidar com uma situação, A possui vários métodos (estratégias), enquanto B não os possui.

Definição 4: O professor A é mais competente do que o professor B se A e B, diante da mesma situação, o professor A é menos despreparado do que o professor B.

“O desenvolvimento das competências, ao decurso da formação inicial, a experiência e a formação contínua é um problema da sociedade, e não apenas um problema da didática" (VERGNAUD, 2001, p. 1). Dessa forma, a discussão de modo pormenorizada, sobretudo com o viés que buscamos encetar em nossa proposta e discussão, para o caso específico do professor de Matemática, adquire um caráter de relevância e imprescindibilidade.

Por outro lado, assumimos posição concorde com G. Vergnaud quando declara que "o desenvolvimento das competências é um viés essencial para a Educação e para o Trabalho. È necessário um quadro de desenvolvimento para refletir sobre tal questão e organizar metodologias para a pesquisa" (VERGNAUD, 2001, p. 1). Ademais, apesar de ter adquirido uma posição singular dentro da teoria dos Campos Conceituais e no contexto da teoria da Conceptualização da ação que buscamos significar, com interesse aplicado ao caso do professor, resgataremos uma última definição importante em sua teoria, que repercute para uma interpretação essencialmente cognitivista para a noção de competência profissional.

Definição 5: Um esquema é uma forma invariante de organização de atividade do sujeito para uma classe de situações determinadas. (VERGNAUD, 2007, p. 7).

A definição 5 requer uma maior reflexão, na medida em que, constatamos uma mudança de perspectiva e de tratamento para a noção de esquema (e invariante operatório) no interior da (DP), a partir das explicações de Pastré, Mayen e Vergnaud (2006), como constatamos a seguir.

L'idée de totalité dynamique fonctionnelle exprime bien ce que Piaget a pu concevoir il y a trois quarts de siècle; mais l'idée d'organisation invariante de l'activité pour une classe de situations et l'analyse en quatre composantes sont sensiblement plus précises et plus rigoureuses. C'est l'organisation de l'activité qui est invariante, et non l'activité ellemême; le schème s'adresse à une classe de situations, non pas à une situation singulière; il a justement une fonction adaptative, ce n'est pas un stéréotype. Si la connaissance est adaptation, il faut apprécier que ce qui s'adapte ce sont des schèmes et qu'ils s'adaptent à des situations; le couple schème/situation est donc le couple théorique fondamental pour penser l'apprentissage et l'expérience. Il n'y a pas de schème sans situation, mais pas non plus de situation sans schème, puisque c'est le 
schème qui identifie une situation comme faisant partie d'une certaine classe. (PASTRÉ, MAYEN e VERGNAUD, 2006, p. 153).

Assim, a partir de um componente e substrato essencialmente cognitivista, a competência do professor assim compreendida, "leva-nos a ter interesse na própria atividade, e não apenas ao seu resultado. A experiência e aprendizado são adaptações. O conhecimento é adaptação, já nos disse Piaget, e ele especificou: assimilação e acomodação" (VERGNAUD, 2001, p. 4). Nesse sentido, Pastré (2002, p. 11) assume a perspectiva de que, para a análise minuciosa das competências profissionais, precisamos considerar sua invariância e sua faceta de regularidade e, mais ainda, "a flexibilidade e capacidade de adaptação às cirscunstancias" (PASTRÉ, 2002, p. 11). Dessa forma, a noção de competência profissional não poderá ser perspectiva apenas por um viés isolacionista ou estanque de um indívuo (como vemos nas definições $1,2,3,4)$ e, sim, como uma noção e/ou fator cirscunstanciado, não dependente apenas de um campo epistêmico disciplinar e não significativamente discutido pela (DM). Vernaud (2007), por exemplo, produz um exemplo que costumamos neglicenciar a respeito da simbolização, linguagem e da conceptualização necessária em Matemática, quando menciona:

Les aspects langagiers et symboliques sont certes importants dans les mathématiques, mais c'est une erreur récurrente que d'identifier les mathématiques à un langage et de confondre ainsi conceptualisation et symbolisation. Les mots sont importants, mais il faut aller chercher audelà des mots et des observables, ce qui fait la différence entre une manière de faire et une autre, même si le sujet n'a pas toujours les mots pour le dire. On peut se tromper facilement. Dans un travail collectif, par exemple, les gens ne s'interrogent pas toujours sur les mots les plus efficaces pour communiquer avec autrui. Existent aussi des formes implicites de communication, sans qu'on soit obligé d'expliciter les conceptualisations sous-jacentes. (VERGNAUD, 2007, p. 4).

Ocorre o mesmo processo de conceptualização envolvendo a comunicação entre os principais sujeitos do entorno (professores do mesmo posto de trabalho), diante de execução de tarefas e atividades profissionais. Depreendemos, a partir do pensamento anterior, que aspectos corriqueiros, envolvendo o uso da linguagem profissional (do métier), tanto podem encerrar um significado de encapsução de esquemas cognitivos e podem ser percebidos na atividade (matemática), bem como, uma outra instância do mesmo fenômeno, quando objetivamos aspectos corriqueiros, envolvendo o uso da linguagem e/ou de um repertório ou jargão 
profissional (do métier) circunstanciados e endereçados ao campo das atividades profissionais e modelos cognitivos, em ambos os cenários, responsáveis pela otimização das atividades.

Do ponto de vista do segundo caso, da atividade no trabalho e os princpipios de otimização e regulação, entram em cena os princípios da Ergonomia Cognitiva, que podem fornecer um ponto de vista diferenciado para a compreensão da atividade do professor de Matemática. Dessa forma, uma análise das situações dinâmicas e os conhecimentos tácitos profissionais mobilizados em situação de trabalho adquirem um valor fundamental (ALVES, 2017; 2019; 2020). Aqui, a competência consiste em articular (com velocidade, confiabilidade, economia, elegância) os conhecimentos do resultado às suas próprias ações e, como também, aos próprios conhecimentos internos e necessários ao sistema escolar brasileiro.

De fato, os sistemas de controle escolar são eminentemente complexos e, a depender de um repertório de experiências anteriores do professor, se mostra impossível controlar sua ampla totalidade em um campo ou posto de trabalho. A Ergonomia Cognitiva se interessa, por exemplo, por um conjunto de conhecimentos aplicados e estratégias eficazes que não podem apenas repousar sobre um conjunto de regulações retroativas no sistema, mas, também, a capacidade de reação e da fina percepção de um desequilíbrio e tácita correção necessária na atividade do trabalhador e, de modo particular, a capacidade de reação do professor em situação.

Por seu turno, Pastré (1999) indica alguns postulados que permitem compreender o nível de significação da noção de competência profissional. O primeiro postulado diz respeito a caráter de homogeneidade das situações de trabalho que, no caso do professor de Matemática, podemos interpretar que o sistema escolar brasileiro considera um posto de trabalho em uma determinada unidade escolar semelhante ou idêntico ao mesmo posto de trabalho em qualquer outra unidade escolar. Tal identificação permite forte ligação e avaliação por intermédio de noção de competência e a qualificação (reconhecimento social da competência). Por outro lado, os conhecimentos são organizados segundo um corpus de conhecimentos, coerentes e estruturados e, de modo particular, constatamos as mesmas características organizacionais e estruturais dos saberes matemáticos científicos (le savoir scientifique).

Não obstante, como esclarece Pastré (1999, p. 113), "se torna necessário para cada métier extrairmos um corpus estável de capacidades, que podem superar situações imprevistas e a evolução do trabalho". De modo semelhante, no caso do professor de Matemática, correspondentemente a um corpus de conhecimentos definidos, indicados por documentos 
normativos e fontesv oficiais se mostra necessário um conjunto de capacidades e habilidades profissionais socialmente reconhecidas e compartilhadas por um grupo de profissionais (professores) de um mesmo posto de trabalho e reconhecido socialmente pela relevância social da atividade que executa no sistema escolar brasileiro.

Observamos que "em qualquer trabalho, ainda mais em trabalho complexo, há vários perigos que não correspondem a uma resposta pronta" (Leplat, 2006: 9). Assim, assumindo uma posição de acordo com Leplat (2006), vislumbramos o surgimento de obstáculos profissionais nos três planos de análise separados da atividade e ação do professor de Matemática (plano da sala de aula, plano do posto de trabalho e no plano da instituição escolar). A ação do professor, portanto, responde a um objetivo e, de maneira indiscutível, entendemos diferentes objetivos em termos de atividades, no local de trabalho e no plano mais geral da profissão. Por exemplo, registre "que um professor em formação é assim levado a entender que um gesto profissional é, em si mesmo, portador de valores, é parte dos fins da escola e, como tal, deve ser trabalhado e questionado não apenas como um gesto técnico, mas como um gesto significativo "(VINATIER \& PASTRÉ, 2007, 106).

Assim, a noção de gesto profissional envolve algumas ambiguidades e valores sociais, conforme Leplat (2013). Para o autor, tais gestos possuem uma determinada relevância, tendo em vista que "podem ser compreendidos como gestos próprios a uma atividade relevante do domínio profissional" (LEPLAT, 2013, p. 16). Um gesto profissional pode se constituir como um indicativo de uma nova competência presumida, todavia, não constitui seu conteúdo essencial. De fato, podemos deparar um gesto profissional observável destituído de uma competência presumida correspondente a um professor de Matemática, bem como, uma suposta competência significada por intermédio de gestos diversos ou pouco difusos do mesmo. Em qualquer circunstância, devemos reconhecer seu caráter de multifuncionalidade e suas repercussões para a análise da coordenação das ações que, de forma especial, constitui um interesse para a (DP) (MAYEN e METRAL, 2008; MAYEN e GAGNEUR, 2017).

No contexto da (DP), temos a possibilidade de levar em consideração vários elementos desconsiderados da teoria piagetiana. No caso da Matemática, por exemplo, poderíamos recordar que "o gesto é o melhor protótipo do conceito de esquema. Eu argumento que o pensamento é um gesto, especialmente o pensamento matemático. Nós precisamos nos beneficiar desta metáfora ousada" (VERGNAUD, 2007, p. 5). Por outro lado, deparamos um 
interesse semelhante ao de Vergnaud quando consultamos, por exemplo, os trabalhos de Leplat (2013), ao discutir o componente pragmático do uso de gestos (ou metáforas) no trabalho. Tendo em vista seu intento de delimitar o campo e o objeto de estudo, Leplat (2013, p. 3) explica que "para fornecer uma definição precisa na presente investigação, propomos a definição seguinte: um gesto é um movimento humano ao qual é atribuído uma significação”. De imediato, segundo sua definição, compreendemos que a significação de um "gesto" dependerá de quadro de referência e, a incorporação de sua análise em pesquisa concorre, também, para o desvelamento dos fenômenos da aprendizagem profissional do professor de Matemática.

Antes de finalizar, acentuamos um ponto de vista clássico originado dos estudos Fauverge (1952) e a análise do trabalho, sob a adoção do Método clínico visando a observação e coleta de dados. Nesse sento, Clot e Leplat (2005, p. 295) recordam que Fauverge preconizava o uso de uma combinação de testes preestabelecidos, visando a análise pormenorizada do trabalho. "O mesmo forneceu um exemplo de uma habilidade chamada de 'coup d'œil' e assinala que a mesma pode ser observada, em várias situações de trabalho e, cada vez, em um sentido diferente" (CLOT e LEPLAT, 2005, p. 295).

A mesma expressão ('coup d'œil') que proporciona uma qualidade perceptível da noção de competência profissional se revela, por exemplo, no pensamento de Sauriau (1881), em seu livro intitulado A teoria da invenção (Théorie de l'invention), publicado em 1881 e o mesmo autor descreve uma habilidade cognitiva denominado de "pensamento lateral” (penser à cótê). De modo prosaico, tal habilidade cognitiva notada, de modo representativo, no professor de Matemática experiente capacita-no antever, por exemplo, que um argumento considerado resolutivo para uma situação problema poderá culminar em uma flagrante contradição ou, também, um comportamento não esperado do modelo matemático. De forma completamente semelhante, por intermédio do "pensamento lateral" ou o emprego de 'coup d'œil', ao decurso da atividade e execução de tarefas, o professor poderá antever determinados elementos indesejados ao funcionamento das atividades no sistema. Desta situação, decorrem gestos profissionais ou determinados jargões que devem transmitir aos estudantes a necessidade de substituição, rejeitar ou eliminar determinado argumento ou estratégia resolutiva.

Diante do exemplo anterior e outros apontados, observamos a conveniência de resgatar uma crítica a respeito da teoria proposta por Piaget, justamente por desconsiderar, de modo 
substancial, fatores intrinsecamente derivados da natureza intrinseca das situações e suas características. Nesse caso, Pastré (2002) acentua o seguinte entendimento critico.

Si la théorie opératoire en était restée là, il n'aurait pas été possible de s'en inspirer pour l'analyse du travail, sauf à chercher dans celle-ci des traces du stade atteint par un sujet adulte à un moment de son développement. Il manque en effet à la théorie piagétienne une prise en compte des situations et de leurs caractéristiques. Le modèle théorique piagétien reste enfermé dans sa dimension génétique, au sens où le développement est pensé comme un processus maturationnel interne. Il est très peu sensible au poids des situations, comme à l'importance des médiations effectuées par autrui. (PASTRÉ, 2002, p. 11 - 12).

Depreendemos, pois, uma preocupação semelhante, tanto da (DM) e pela (DP), do primado originado da consideração das características das situações, tanto de aprendizagem para o estudante, bem como de aprendizagem do próprio professor no interior de seu campo profissional. Com origem neste e em outros argumentos, na seção subsequente, apresentaremos ao leitor alguns elementos preliminares de uma proposta visando o uso de ambas as teorias em pesquisa que elege a necessária compreensão dos fenômenos que concorrem para o desenvolvimento profissional.

\section{Uma perspectiva de complementaridade da (DM) e da (DP) visando o uso de uma Engenharia Didática de Formação (EDF)}

Em nossos trabalhos temos acentuado uma perspectiva de complementaridade envolvendo o uso e visando a pesquisa balizada pelos pressupostos que desenvolvemos com a (DM) no Brasil. Como buscamos evidenciar nas seções predecessoras, o triangulo didático clássico propugnado por Broussau (1986a), cujos elementos são professor - estudante - saber (ver figura 1), diz respeito ao interesse de um conjunto de fenômenos fortemente condicionado pelo próprio campo epistêmico científico matemático. Por outro lado, com um ponto de vista afetado também pela (DP) descortinamos um conjunto de práticas e fenômenos eminentemente condicionados pelo campo pragmático das atividades e circunstanciadas pelo campo profissional.

Como mencionamos de modo en passant na introdução, um processo natural de refundação e rediscussão de determinados interesses para a (DM) ocorreu, na medida em que, paulatinamente, a atividade do professor foi considerada e rediscutido o seu papel para o 
desenvolvimento de Engenharias Didáticas $(\mathrm{ED})^{3}$ desenvolvidas na França e endereçadas ao campo da Matemática, como também em outras áreas. Perrin-Glorian (2004) indica uma mudança de perspectiva necessária visando, também, uma melhor compreensão do papel do professor e os determinantes/obstáculos em sala de aula.

Je voudrais quand même dire que la recherche en didactique doit prendre dans son champ d'étude la question de la formation des enseignants et, en amont, celle de l'étude du rôle de l'enseignant dans l'enseignement des mathématiques et des pratiques ordinaires des enseignants. Elle a commencé à le faire et les recherches dans ce domaine se développent beaucoup depuis une dizaine d'années. Dès la fin des années 80 et le début des années 90, les difficultés de transmission des ingénieries didactiques et les nécessités de la formation amènent les didacticiens à faire un peu plus de place à l'enseignant dans leurs objets d'étude, écartant la tentation première de se substituer à lui. L'objet d'une recherche scientifique est la production de connaissances et non la modification du système. Cependant, pour que les recherches en didactique soient utiles aux enseignants et à terme puissent avoir une influence sur la formation des enseignants, il faut d'abord mieux comprendre les déterminants de l'action de l'enseignant en classe. (PERRIN-GLORIAN, 2004, p. 74 - 75).

Por outro lado, diversos trabalhos de Pastré (2002) revelam a forte impregnação dos interesses da (DP) e um "fio condutor" que permite interpretar algumas noções clássicas da (DM) quando inseridas em um cenário epistêmico endereçado ao campo das atividades profissionais e, acrescentamos, as atividades do professor de Matemática, embora suas reflexões a respeito da $(\mathrm{DM})$ ainda não provocaram um avanço teórico representativo.

Em nossos trabalhos temos acentuados a adoção em processos investigativos voltados para a formação e o desenvolvimento profissional do professor de Matemática (Alves, 2019, 2020). Nesse caso, propugnamos que os pressupostos de uma Engenharia Didática de Formação (EDF) (ou de segunda geração), como introduzida pela primeira vez por Perrin-Glorian (2011) requer uma maior atenção e sua adoção, de forma substancial, em território brasileiro, posto que, ainda distinguimos um cenário rarefeito e localizado de ações acadêmicas e a ausência da produção substancial de dissertações e/ou teses de doutorado desenvolvidas, com o amparo dos

\footnotetext{
${ }^{3}$ Boterf (1985) assinalou uma cultura europeia fundamentada e relativizada com a abordagem do engenheiro. $\mathrm{O}$ mesmo foi o primeiro autor a empregar o termo engenharia educativa (ingénierie éducative), que se manifestou ao longo dos anos 60. Tais engenharias afirmaram uma preocupação metodológica em um contexto de formação geral e requerem uma distinção e da repercursão do desenvolvimento de engenharias didáticas endereçadas para a aprendizagem em Matemática e na (DM).
} 
fundamentos de uma (EDF) (ALVES, 2018d). Não obstante, urge não assumir um ponto de vista ingênuo, dando conta do interesse hermético de se desenvolver pesquisas balizadas pela (EDF), segundo os moldes e um pensamento derivado de uma cultura claramente europeia e, antes de tudo, uma cultura francesa.

Perrin-Glorian (2010) assinala, logo em seguida, de modo preciso, os fenômenos originados das interações entre teoria-prática, aos conhecimentos originados pelas teorias, com forte teor de epistemização (savoir théoriques), enquanto que, os conhecimentos práticos (savoir pratiques) originados da prática e das atividades, também, com fortes componentes de pragmatização e condicionados pela realidade.

Je distingue ici les savoirs des connaissances qui sont liées à la personne et disparaissent avec elle, et qui sont, avec les compétences qui permettent de mobiliser ces connaissances à bon escient, des moyens d'agir, de prendre des décisions. Cela ne recouvre pas tout à fait la distinction entre théorie et pratique: il peut y avoir des savoirs pratiques, issus de l'expérience, qui n'ont pas nécessairement valeur générale et des savoirs théoriques peuvent être transformés en connaissances qui permettent de prendre des décisions pratiques. (Perrin-Glorian, 2010, p. 44).

Adotamos uma perspectiva de complementaridade, implicando as hipóteses de (DM) conjuntamente com a (DP), considerando que a (DM) fornece uma interpretação rica de fenômenos intimamente relacionados e condicionados pelo campo matemático epistêmico. E, também somos levados a considerar os interesses declarados pelo (DP) para fornecer uma análise teórica e psicológica do trabalho do professor, uma vez que leva em conta os processos de aprendizagem adquiridos e necessários para adultos e, em particular, dos professores de Matemática, a fim de gradualmente desenvolver suas habilidades profissionais, de incorporar modelos cognitivos de eficiência ao longo do tempo e que permitem revelar um viés perceptível de sua competência profissional.

Cabe observar como objetivo maior a validação teórica das situações provenientes de uma (ED), sua capacidade de produzir conhecimento matemático, a identificação de escolhas fundamentais para uma (ED), separando o que se mostra essencial do que se mostra vinculado a um contexto particular e que pode ser adaptado ou modificado. "Tal realização associada toma espaço em um lugar ou ambiente protegido e sob controle pelos pesquisadores, no caso de uma Engenharia Didática de Pesquisa” (ARTIGUE, 2015, p. 492). 
Mas, para um segundo nível de uma (ED), se constata que "o objetivo é o estudo da adaptabilidade de situações validadas a partir de classes ordinárias com professores que não foram envolvidas na primeira fase" (ARTIGUE, 2015, p. 493), todavia, se podem acentuar o interesse imprescindível pela elucidação de conteúdos matemáticos e as organizações possíveis para tais conteúdos, agregado ao interesse de possíveis dificuldades dos estudantes para a aprendizagem de tais conteúdos (PERRIN-GLORIAN e BELLEMAIN, 2016, p. 38). Neste ponto, com origem em um pensamento de Perrrin-Glorian e Bellemain (2016), se vislumbra um movimento dialético distinguido, na medida em que se revela um interesse pela negociação e a introdução de situações didáticas profissionais (SDP) aos professores e, no segundo nível, são tomados como objeto de estudo, acrescido do próprio impacto de uma (EDF) e suas consequências visando a formação desses profissionais e que pode ser compreendido por intermédio do esquema proposto por Tempier (2013, p. 187), segundo o modelo indicado:

\section{pesquisa $\rightarrow$ engenharia $\rightarrow$ desenvolvimento $\rightarrow$ ensino .}

Uma implicação imediata de interesse, para o caso de Engenharia Didática de Desenvolvimento ou Engenharia Didática de Formação (EDF) é que os constructos de uma (ED), de per si, se tornam um corpus de conhecimentos para os professores e a sua necessária disseminação entre demais profissionais do ensino, com o potencial de afetar e modificar determinados roteiros para uma transposição didática (CHEVALLARD, 1991) e, consequentemente, uma transposição profissional planejada e sistemática. (Alves, 2020).

Por outro lado, não podemos deixar de mencionar um aspecto ou circunstância pouco discutida no interior da (DM) e que, concernentemente aos estudos desenvolvidos em Psicologia do Trabalho, adquiriu maior atenção e trato sistemático investigativo. Para exemplificar, nos reportamos ao pensamento de Clot e Leplat (2004) quando alertam que a observação de um observador produz/estimula a produção de um conhecimento que não podemos ignorar/desprezar: "o desenvolvimento da observação originada da própria observação. Um dos efeitos mais desconhecidos da observação é precisamente os efeitos que ela provoca na atividade do observado". (CLOT e LEPLAT, 2004, p. 302). Por conseguinte, para o corpus teórico constitutivo para o desenvolvimento de uma (EDF), a partir da hipótese de uso dos pressupostos da (DM) e da (DP), temos um cenário relativamente mais afeito e propenso para registrar as consequências da investigação sobre os próprios indivíduos investigados e, em nosso caso, dos professores de Matemática em formação inicial ou continuada (ALVES, 2019, 2020). 
Para finalizar, na tabela 1 indicamos alguns elementos importantes para a nossa proposta inicial de complementaridade teórica e de uso em pesquisa da (DP) e da (DM), a partir de um design investigativo que visa o desenvolvimento de um itinerário de uma (EDF). Nela, apresentamos a descrição de algumas noções que podem consubstanciar um campo de aplicação da (DP) visando a produção ulterior de estudos com interesse na aprendizagem do professor de Matemática, no e a partir do seu próprio trabalho e os princípios reguladores de sua competência profissional. Decerto que não assumimos ou buscamos um estádio definitivo, todavia, introdutório e dialógico para a presente proposta teórica que ainda se insere em um cenário de vácuo, concernentemente ao desenvolvimento de pesquisas acadêmicas com tal matiz teórico em nosso país.

Ademais, cabe distinguirmos os quadros de referencias costumeiramente consusbstanciados no locus acadêmico, da tradição francesa, e que concorreram para confirmar uma identidade acadêmica e científica de modo distinto, tanto para a (DP) e para a (DM). No primeiro caso, não podemos negligenciar uma perspectiva de Engenharia Pedagógica ou Engenharia de Formação (EF) propalada na França e oriunda de um contexto de formação profissional continua de adultos. Por outro lado, quando discriminamos a terminologia Engenharia Didática de $2^{\circ}$ geração ou Engenharia Didática de Formação (EDF) objetivamos um quadro evolutivo de um design de investigação originado da (DM) e profundamente demarcado e condicionado pelo campo epistêmico disciplinar.

Com origem em um cenário europeu ampliado, Boterf $(1999$, p. 1) recorda que a noção de engenharia (d'engineering) ocorreu no começo deste século, antes da segunda Guerra Mundial, nos Estados Unidos, Alemanha e Grã-Bretanha. Na França, tal noção se mostrou mais representativa apenas após a segunda guerra. Ademais, “a noção de Engenharia de Formação surgiu na França ao decurso dos anos 60 e três fatores concorreram para tal contribuição: a demanda de pais novamente independentes, a entrada de engenheiros no domínio de formação, a legislação sobre formação continua" (BOTERF, 1999, p. 2). Por outro lado, Leclercq (2002) explica e distingue na Europa três vertentes de atividades: engenharia social (l'ingénierie sociale), engenharia de formação (l'ingénierie de formation) e engenharia pedagógica (l'ingénierie pédagogique). Dessa forma, urge uma compreensão ampliada sobre a noção de Engenharia disseminada, a posteriori, no campo da (DM) e que se consubstanciou como uma engenharia pedagógica (PARMENTIER, 2008), que evoluiu para uma engenharia de formação 
ou de profissionalização (FERNAGU-OUDET, 2004) e adquiriu um itinerário marcadamente singular no território francês e não apenas restrito ao campo da Matemática. Leclercq (2002) apresenta um cenário explicativo na figura abaixo, dando conta de categorias de engenharia.

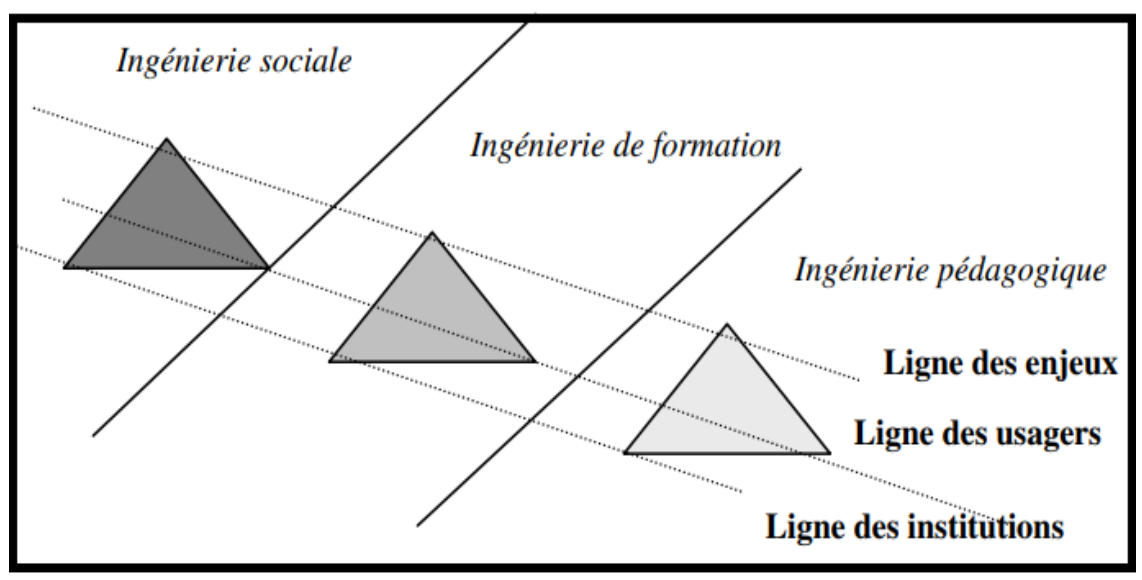

Figura 2. Leclerqc (2002) descreve as atividades desenvolvidas nas vertentes das categorias de Engenharias desenvolvidas na Europa.

Antes de finalizarmos esta pequena digressão sobre (EF) e retornarmos ao nosso campo maior de interesse, trazemos o expediente de análise exógena de Hebrard (2011), na medida em que desenvolve um expediente de apreciação e distinção das definições ou concepções de Engenharias de Formação (EF) disseminadas na Europa. Tal reflexão busca evitar um entendimento puramente endógeno atinente a um processo de (EDF) endereçada, de modo particular, ao professor de Matemática (TEMPIER, 2013).

A l'examen des principales définitions de l'ingénierie de la formation, il apparaît qu'elles se caractérisent par une insistance sur la dimension méthodologique, les instruments, les outils, qu'elles se réfèrent à la notion de système et au paradigme systémique, qu'elles affirment s'appuyer sur la combinaison de connaissances issues de différentes sciences et techniques (rarement nommées), voire sur une "science de la formation". De plus elles distinguent d'une part des étapes : de l'amont, l'étude du contexte, des besoins et demandes, à l'aval, l'évaluation, en passant par la conception et la conduite de l'action et, d'autre part, des niveaux de responsabilité et de décision : celui des politiques de formation, celui de l'organisation des dispositifs, plans ou actions de formation et enfin celui de la pédagogie. Chacun de ces niveaux de responsabilité correspond à une catégorie d'acteurs: les décideurs politiques nationaux ou régionaux, pour le niveau des politiques publiques, les membres de la direction des entreprises pour les politiques de formation, les responsables de formation et la hiérarchie intermédiaire pour le niveau organisationnel, les formateurs et "les 
individus" pour le dernier niveau : celui de la mise en oeuvre de l'activité pédagogique dans les situations de formation (HEBRARD, 2011, p. 112)

Não obstante, apesar do caráter de relevância de compreendermos um entorno histórico e social que concorreu para uma maior "capilaridade científica" para a noção de Engenharia no continente europeu, nossa perspectiva de complementaridade restringir-se-á a um campo epistêmico definido, com forte aderência ao saber matemático científico. Nesse sentido, assumimos posição concorde com Bachero e Bosh (2015), quando relatam uma experiência de desenvolvimento de um design que se identifica como uma Engenharia Didática Clássica ou de $1^{\mathrm{a}}$ geração aplicada ao campo de formação de professores. De fato, os autores esclarecem que:

Usually, in the development of a didactic engineering process, researchers presented a teaching proposal partially including the a priori analysis (goals expected, problems addressed, strategies forecast) to the team of teachers. Then they jointly elaborated the details of the sequence of lessons up to the preparation of a didactic card (fiche didactique) for each lesson. Researchers prepared the observation and decided on the kind of data to be gathered. During the lessons, observers had to try to be as invisible as possible, and teachers were supposed to forget that they were observed, taking their own decisions about the teaching of the lessons. Immediately after each lesson, a short meeting took place for the teacher, researchers, and other possible observers to share impressions, starting with the teacher's. (BACHERO e BOSH, 2015, p. $258-259)$.

$\mathrm{Na}$ figura 3, divisamos claramente o roteiro investigativo para uma (ED): analises preliminares, design e análise a priori, implementação e coleta de dado, análise a posteriori. Nesse caso, Bachero e Bosh (2015) relatam um percurso desenvolvido e balizado pelos pressupostos da Teoria Antropológica do Didático (TAD). A despeito de apoiarem sua pesquisa em um caráter de complementaridade, seu interesse difere do nosso, pelo fato de que, o desenvolvimento de (EDF), a partir dos pressupostos de (DP) e da (DM) envolve considerar o primado cognitivista dos fenômenos originados das interações dos elementos dispostos na figura tetraédrica (ver figura 1). 


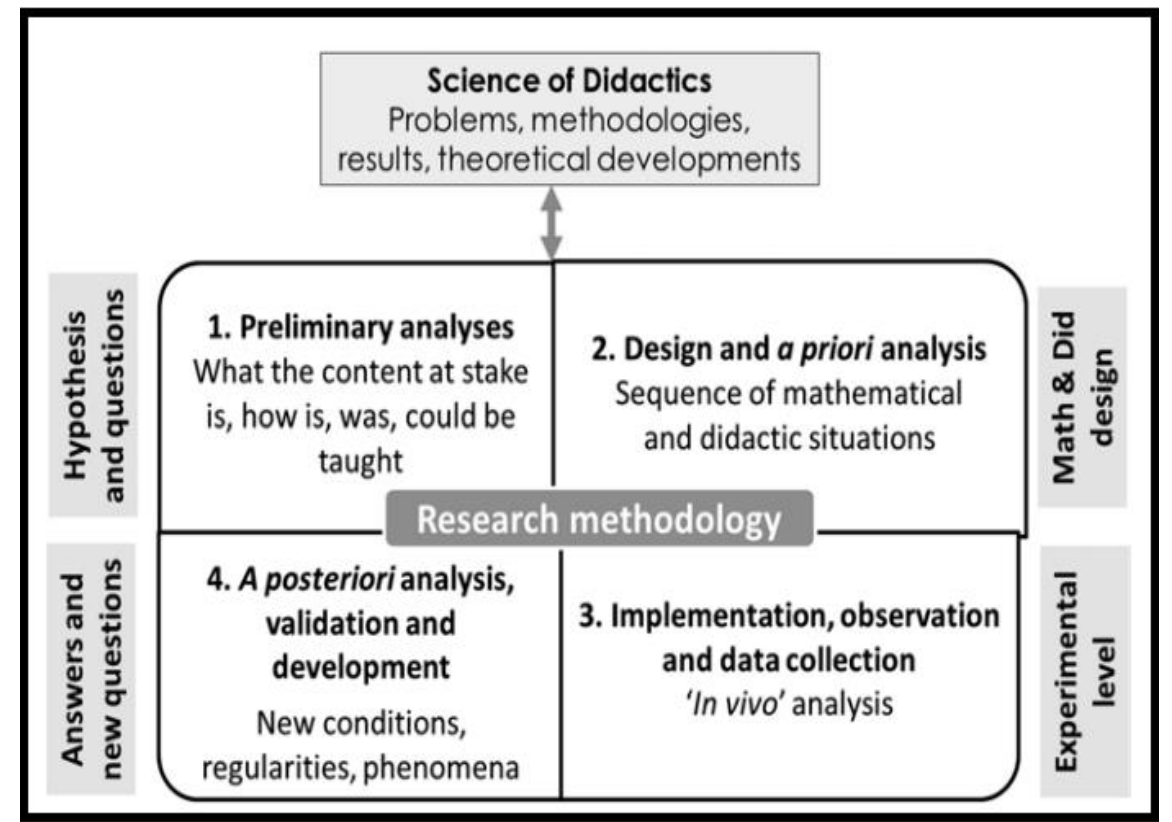

Figura 3. Bachero e Bosch (2015, p 252) descrevem o uso da noção de engenharia em caráter de complementaridade com a Teoria Antropológica do Didática (TAD)

Isso posto, cabem alguns ajustes finais da nossa proposta. Com efeito, a partir de um ponto de vista originado na (DP), propugamos considerar em pesquisa, por exemplo, um outro viés (ou relação) para o contrato didático que, originalmente introduzido por Brousseau (1986a; 1986c), costumou evidenciar apenas as relações endereçadas ao próprio estudante e, agora, mencionamos e introduzimos a noção de contrato profissional ou ainda uma noção de contrato de ensino que, com origem em um cenário de relações essencialmente profissionais e pragmáticas, se define circunstanciado a partir de um conjunto de regras deodônticas partilhadas entre profissionais, sendo observadas e seguidas pelos professores de Matemática de um determinado posto de trabalho, em alguma instituição escolar. O contrato de ensino diz respeito, também, a um conjunto de determinações/relações (nem sempre explicitas) que devem ser seguidas e respeitadas pelo professor (e pelos seus colegas de profissão). Margolinas (1988) revela e confirma a existência de tal contrato (contrat d'enseignement), quando afirma que:

L'enseignant est lié à la société par ce que nous pouvons appeler un contrat d'enseignement. Ce contrat, comme le contrat didactique qui régit le fonctionnement de la classe, est le plus souvent non explicité, ou non explicitable. Il fait partie des lois du système didactique. li n'est pas immuable, mais il n'est pas du ressort d'un individu de le modifier, car il engage plusieurs partenaires. (MARGOLINAS, 1988, p. 54). 
Ademais, de modo substancial, a noção de obstáculo epistemológico foi inserida na (DM) e, agora, diante dos pressupostos assumidos até aqui, objetivamos a noção de obstáculo profissional, cujas referenciais históricas podem ser detectadas em estudos clássicos da vertente de estudos da Psicologia do Trabalho. Por conseguinte, a consideração de efeitos parasitas e fatores resilientes à atividade, a constatação de ausência de regularidade e lenta estabilidade dos esquemas (cognitivos) de ação, quando cirscuntancidos pela execução de tarefas profissionais, consubstanciam e caracterizam um obstáculo profissional e, como registramos a função dos conceitos pragmáticos, sua superação poderá significar e revelar uma espécie de transição entre um (professor) profissional inexperiente (noviço) de um professor experiente (expertise).

Brousseau (1986) descreveu de modo pioneiro a noção de contágio epistemológico no campo da (DM). Agora, sob um ponto de vista afetado pela (DP), propugnamos a noção de contágio profissional, quando reconhecemos um conjunto de regras, de modo geral não explicitas, todavia, partilhadas pelo modus operandi a esquemas de ações típicos e que se enquadram em um viés de identidade e estabilidade característica dos profissionais (professores) que estão cirscuncritos por um mesmo posto de trabalho. Assim, um noviço (professor inexperiente), ao receber a tarefa de assumir uma função inédita nesse posto de trabalho, mesmo que o individuo possua, inicialmente, um modus operandi que garanta sua adaptação imediata ao posto e o reconhecimento dos seus pares, ao decurso do tempo, seus esquemas de ação e de antecipação, sua capacidade de lidar com os problemas circunscritos ao respectivo posto, cada vez mais, se mostram semelhantes ou idênticos ao respectivo trato dispensado pelos demais professores do mesmo posto. Não obstante, em um sentido contrário, pode ocorrer um princípio de imunização profissional, no sentido de que, ao longo de sua carreira, os processos inerentes de economia e simplificação de ações provocam uma espécie de “distanciamento cognitivo" ou envolvimento seletivo na medida do estritamente necessário para lidar com problemas de ordem diversa, nos três planos caracteristicos de trabalho do professor de Matemática.

Broussseau (1996, p. 73) fala da "epistemologia" do professor a partir de um ponto eminentemente demarcado pelo conhecimento matemático, na medida em que o professor precisa explicitar um método para produção de respostas dos estudantes e, em última instância, deve possui uma competência profissional para "resolver os conflitos do contrato didático" (BROUSSEAU, 1996, p. 73). Por outro lado, propugnamos uma apreciação que toma como referência aos próprios colegas do posto de trabalho e, relativamente ao seu grupo profissional, 
o mesmo professor de Matemática necessita de eficiência para resolver os dilemas e os entraves originados do contrato profissional e, além disso, precisa adquirir uma imagem privada de si próprio como um profissional compentente (auto-imagem), de tempos em tempos confirmada pelos colegas (companheiros) que executam e que reproduzem atividades profissionais semelhantes. Tal imagem profissional, quando não confirmada pelo grupo de colegas, ao decurso do tempo, concorrem para a substituição e indicação de outro representante para o grupo, cuja capacidade e competência servirão como paradigma para os demais.

No âmbito da (DP), propugnamos ainda a noção de institucionalização profissional, envolvendo a adoção de primazia de um conjunto de saberes ou regras indicadas por um profissional, cujo expertise (reconhecido no métier) suplanta e se distingue de todos os demais. Quando desenvolvemos uma análise de um grupo de profissionais, de modo natural e sob o viés do campo pragmático em campo de atividade, de modo recorrente, registramos um ou alguns profissionais adquirem maior reconhecimento ou ampla representatividade do grupo profissional. Neste caso, em maior ou em menor substância, seu modus operandi e suas percepções sobre o ensino e atuação profisssional passam a influenciar/condicionar e serem incorporadas à atividade profissional de todos os demais sujeitos do grupo.

Nesse exemplo, como tratam-se de um conjunto de conhecimentos essencialmente pragmáticos, reveladores do sucesso, da eficiência ou êxito de um profissional passará, então, a ser incorporado/empregado pelos demais, sob a égide de um exemplo de um conhecimento pragmático ou modus operandi de sucesso (competência) a ser seguido, replicado e incorporado pelos restantes indivíduos do mesmo posto. No caso da (DM), adotamos definições clássicas e largamente veiculadas na literatura científica.

No Quadro 1 trazemos nossa proposta preliminar de complementaridade.

Quadro 1: Proposta de complementaridade para a DP e a DM segundo os interesses de uma Engenharia de Formação (EDF).

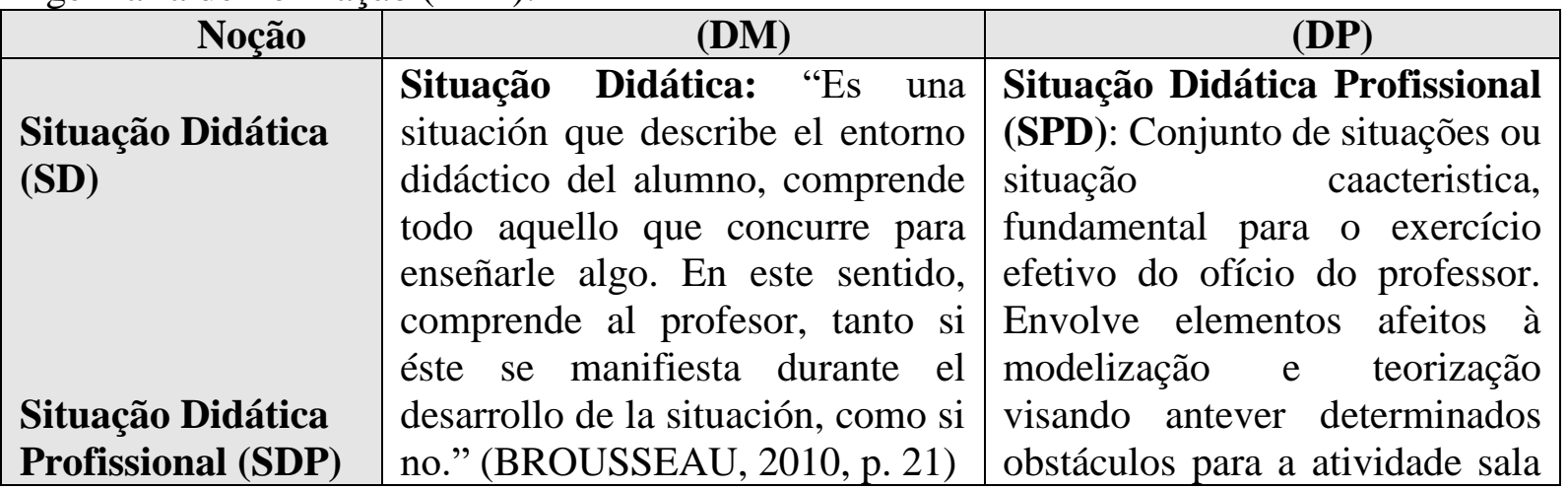




\begin{tabular}{|c|c|c|}
\hline & & $\begin{array}{l}\text { de aula, para a atividade } \\
\text { profissional no posto de trabalho } \\
\text { e na própria instituição. }\end{array}$ \\
\hline Situação a-didática & $\begin{array}{l}\text { Situação adidática: “[...] como } \\
\text { parte essencial de uma situação } \\
\text { didática, é uma situação na qual a } \\
\text { intenção de ensinar não é revelada } \\
\text { ao aprendiz, mas foi imaginada, } \\
\text { planejada e construída pelo } \\
\text { professor. (ALMOULOUD, 2007, } \\
\text { p. 33) }\end{array}$ & $\begin{array}{l}\text { Situação Profissional (SP): } \\
\text { Conjunto de situações } \\
\text { profissionais, recorrentes e no } \\
\text { exercício cotidiano do métier, } \\
\text { todavia, sem um interesse } \\
\text { explícito ou intenção de } \\
\text { modelização e a teorização } \\
\text { objetivando o aprendizado do } \\
\text { professor no e do trabalho. }\end{array}$ \\
\hline $\begin{array}{l}\text { Obstáculo } \\
\text { Epistemológico }\end{array}$ & $\begin{array}{l}\text { Obstáculo Epistemológico: "Os } \\
\text { obstáculos epistemológicos são } \\
\text { identificados nas dificuldades que } \\
\text { os matemáticos encontraram, na } \\
\text { história, para a compreensão e } \\
\text { utilização desses conceitos". } \\
\text { (ALMOULOUD, 2007, p. 139) }\end{array}$ & $\begin{array}{l}\text { Obstáculo Profissional: } \\
\text { Constituem entraves, barreiras, } \\
\text { situações profisionais típicas e } \\
\text { recorrentes registradas no } \\
\text { interior da atividade e na ação } \\
\text { necessária do professor para o } \\
\text { exercício do ofício e que } \\
\text { produzem lentidões para sua } \\
\text { realização, tendo em vista o } \\
\text { alcance de um estádio } \\
\text { perceptível e final da ação, e que } \\
\text { corresponde com a expectativa } \\
\text { da instituição. }\end{array}$ \\
\hline $\begin{array}{l}\text { Contráto de Ensino } \\
\text { ou Contrato } \\
\text { Profissional }\end{array}$ & $\begin{array}{l}\text { Contrato Didático: Conjunto de } \\
\text { regras, geralmente não explicitas e } \\
\text { que, contudo, sua estabilidade } \\
\text { possibilita aos estudantes o } \\
\text { progresso de suas atividades. Tal } \\
\text { noção foi introduzida de forma } \\
\text { piomeira por Brousseau (1988). } \\
\text { Relação: professor - estudantes. }\end{array}$ & $\begin{array}{l}\text { Contrato Profissional ou de } \\
\text { Ensino: Relações estabelecidas } \\
\text { entre professor - instituição e } \\
\text { que determina, de modo } \\
\text { implícito, um conjunto de regras } \\
\text { que devem ser seguidas pelo } \\
\text { professo, enquanto que, se } \\
\text { observam um conjunto de regras } \\
\text { deondonticas implícitas, que } \\
\text { devem ser seguidas pelos } \\
\text { colegas de um posto de trabalho, } \\
\text { mediante as expectativas } \\
\text { definidas por cada instituição } \\
\text { escolar. } \\
\text { Relação: professor - instituição }\end{array}$ \\
\hline Competência & 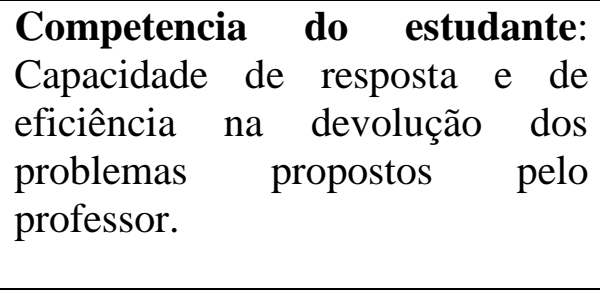 & $\begin{array}{l}\text { Competência do professor: } \\
\text { Consiste no caráter de } \\
\text { invariância, regularidade e } \\
\text { plasticidade diante do } \\
\text { gerenciamento de problemas não } \\
\text { trivais no plano da sala de aula, }\end{array}$ \\
\hline
\end{tabular}




\begin{tabular}{|c|c|c|}
\hline & & $\begin{array}{l}\text { no plano do posto de trabalho e } \\
\text { no plano institucional e/ou } \\
\text { educacional. }\end{array}$ \\
\hline Contágio & $\begin{array}{l}\text { Contágio } \\
\text { Epistemológico: } \\
\text { Processo de alteração, } \\
\text { modificação da mediação e } \\
\text { atividade do professor derivada do } \\
\text { saber matemático e sua } \\
\text { organização no sistema de ensino. }\end{array}$ & \begin{tabular}{l} 
Contágio \\
\multicolumn{2}{c}{ Profissional: } \\
Processo adaptativo e de \\
incorporação de práticas \\
preexistentes e que reforçam \\
uma identidade e estabilidade de \\
ações no exercício do metier.
\end{tabular} \\
\hline $\begin{array}{l}\text { Institucionalização } \\
\text { do saber } \\
\text { matemático } \\
\text { Institucionalização } \\
\text { do conhecimento } \\
\text { profissional }\end{array}$ & $\begin{array}{l}\text { Institucionalização: As situações } \\
\text { definidas como aquelas em que o } \\
\text { professor fixa convencionalmente } \\
\text { e explicitamente o estatuto } \\
\text { cognitivo do saber matemático. } \\
\text { (ALMOULOUD, 2007, p. 40) }\end{array}$ & $\begin{array}{l}\text { Institucionalização } \\
\text { profissional: Situações } \\
\text { Profissionais em que o professor } \\
\text { experiente ou os documentos } \\
\text { normativos de uma instituição de } \\
\text { ensino fixam e determinam o } \\
\text { estatudo de relevância de um } \\
\text { determinado conhecimento } \\
\text { profissional necessário para a } \\
\text { execução de tarefas e atividades. }\end{array}$ \\
\hline $\begin{array}{l}\text { Transposição } \\
\text { didática }\end{array}$ & $\begin{array}{l}\text { Transposição didática: Conjunto } \\
\text { de transformações envolvendo o } \\
\text { savoir savant au savoir enseigné. } \\
\text { (CHEVALLARD, 1991) }\end{array}$ & \begin{tabular}{lcr} 
Transposição & \multicolumn{2}{c}{ profissional: } \\
Conjunto de & transformações \\
sobre os & conhecimentos \\
pragmáticos & caracterizando a \\
transmissão & de & saberes \\
pragmáticos & entre & professores \\
experientes & e & professores \\
inexperientes.
\end{tabular} \\
\hline Devolução & 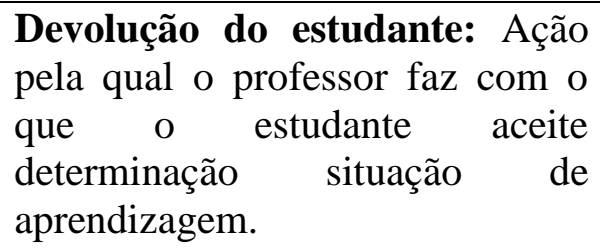 & $\begin{array}{l}\text { Devolução profissional: Ação } \\
\text { pela qual a instituição de ensino } \\
\text { confere um conjunto de regras } \\
\text { (tarefas) que devem ser aceitas } \\
\text { (cumpridas) pelo professor. }\end{array}$ \\
\hline
\end{tabular}

Elaboração: o autor.

Artigue (2009; 2015), Barchero e Bosh (2015) recordam que nos primeiros estudos desenvolvidos de (ED), mediante uma perspectiva de complementaridade com a (TS), se registrou uma perspectiva de investigação inexoravelmente afetada pelos próprios fundamentos (TS). Podemos constatar tal influência a partir dos interesses de pesquisa majotariamente declarados: uma noção central concedida para a noção de situação, uma grande atenção concedida para a epistemologia do conhecimento, a relevância considerada das características do milieu da situação, as características dos estudantes, e sua capacidade produtiva diante de situações a-didáticas, isto é, “isto é, uma adaptação baseada no problema matemático em jogo, 
não sobre a orientação e ajuda do professor ou sobre a referência ao contrato didático" (ARTIGUE, 2009, p. $4-5$ ).

Não obstante, diante dos entraves percebidos nos estudos desenvolvidos e com o viés de uma Engenharia Didática de $1^{a}$ geração ou clássica, resgatamos o seguinte alerta observado por Artigue (2009) que reforça a necessidade de uma agenda de pesquisa (research agenda) visando uma maior compreensão dos modelos de funcionamento, dos princípios reguladores de sua atividade prática profissional do professor de Matemática:

The difficulties met with the transmission of DI realizations have shown the necessity of considering the teacher as a full actor of the didactical situation, of understanding better her contribution to classroom dynamics and its effects, as well as the rationale underlying the decisions she takes. A better understanding of teachers' practices and of the determinants of these becomes thus a priority in the research agenda. (ARTIGUE, 2009, p. 6)

Brousseau (2010), por sua vez, reforça a mesma mensagem endereçada a formação de professores, com origem em um indício não enigmático de que, apesar da grande quantidade de pesquisas desenvolvidas em vários países há décadas, a formação de professores de Matemática ainda se constitui como um merecedor de vigilância constante, ao declarar que:

Il est nécessaire de développer dans les universités, qu'elles soient dévolues à la formation de professeurs ou qu'elles soient généralistes, des équipes d'enseignement et des laboratoires de recherche composites ouverts à des chercheurs d'origines diverses, disposés à prendre place dans les débats scientifiques avec des arguments vérifiables par les autres. (BROUSSEAU, 2010, p. 28)

De modo parcial, assumiremos posição concorde com Artigue (2009), na medida em que, além da necessidade de compreendermos o professor de Matemática como um ator importante de uma situação didática, urge considerarmos e pesquisar dos demais planos de atividade e execução de tarefas do professor e que temos assinalado até aqui, a saber: o plano da sala de aula, o plano do posto de trabalho, o plano da atividade institucional. (ALVES, 2018a; 2018b, 2019, 2020).

Por conseguinte, um design de investigação afetado pelo uso, em caráter de complementaridade para a (DP) e a (DM), não poderá objetivar uma investigação sobre a competência profissional do professor, tomando de forma isolada apenas um desses planos indicados. Consequentemente, de forma sistemática, podemos desenvolver um expediente para 
a análise e a compreensão dos processos de aprendizagem, aquisição de competências especializadas, como consequência direta de um incremento dos esquemas cognitivos, que credenciam o professor de Matemática para lidar com problemas complexos e característicos do itinerário de profissionalização e definição do seu expertise. Podemos estabelecer uma perspectiva comparativa com o estudo de Tempier (2013), endereçado ao desenvolvimento de uma Engenharia Didática de Formação (EDF), com campo epistêmico matemático definido, não obstante, tal variável não se mostra determinante.

Quadro 2. Descrição das fases previstas por uma (EDF), a partir da adoção, em caráter de complementaridade, da (DP) e da (DM), visando a pesquisa endereçada à formação do professor.

\section{Descrição das fases de uma (EDF) a partir de uma proposta de complementaridade envolvendo e (DP) e a (DM)}

\section{Análise}

preliminar:

análise

pragmática das concepções definidas e implicadas em determinado posto de trabalho e de uma instituição. A identificação de obstáculos profissionais, elemento de contagio profissional e a descrição e compreensão do funcionamento do contrato profissional ou contrato de ensino. Identificação e definição das Unidades de Trabalho (UT).

Análise a posteriori: Etapa de confrontação dos dados empírico em contraste com os objetivos e hipóteses assumidas pelo quadro teórico assumito (TS)+(DP).

Fonte: Elaboração do autor.

Para concluir, a despeito dos elementos que buscamos assinalar ao decurso das seções anteriores e uma perspectiva de impregnação para o desenvolvimento de uma (ED) a partir dos pressupostos da (DP) e da (TS), não podemos permitir uma espécie de desnaturalização de princípio científicos que, reconhecidamente, constituem o aparato desenvolvido e sedimentado

estruração de um modelização e Situações Didáticas Profissionais (SDP) tomadas com referência nas Unidades de Trabalho (UT) e a identificação de (SP). Nessa etapa assumimos a equação característica indicada SPD=UT+DP que preserva a importância da noção de situação.

Implementação e observação (análise in vivo): Etapa de observação e coleta de dados. Avaliação dos dados em tempo real ou logo após a experimentação. Ação endereçada para a compreensão do funcionamento dos obstáculos profissionais e do registro de concepções pragmáticas atinentes a uma (SDP). 
por um substrato de uma Ciência da Didática (JOSHUA e DUPIN, 1993), como Barchero e Bosch (2015, p. 251) alertam em seguida.

It may also contribute to the science of didactics with the results obtained and the open problems raised, leading to new theoretical or methodological developments. In this sense, DE is not a development practice where previously established research results are transformed into teaching proposals. It is a way to empirically contrast assumptions about the possibilities of the diffusion of mathematical knowledge and the phenomena hindering it. (BARCHERO e BOSHC, 2015, p. 251).

Por conseguinte, o desenvolvimento de uma (ED) a partir dos pressupostos da (DP) e da (DM), com o uso efetivo da (TS) em sua etapa de experimentação, poderá proporcionar vislumbramos um novo cenário de problemas representativos e relevantes para uma compreensão da aprendizagem do professor do e a partir do trabalho. E, parafraseando Tempier (2013, p. 187), o desenvolvimento de uma Engenharia de Formação, permitindo o questionamento no ensino ordinário, de uma Engenharia Didática ou de uma Engenharia Didática Profissional (Mayen, Olry \& Pastré, 2017) para a pesquisa.

\section{Considerações finais}

Nas seções anteriores discutimos alguns elementos e noções representativas da (DP) e da (DM), envolvendo a proposição de uma perspectiva de desenvolvimento de pesquisas no Brasil, a fim de aperfeiçoar as relações objetivas de investigação visanda a formação acadêmica de professores de matemática (inicial ou continuada). Em particular, destacamos uma apreciação de algumas noções da Teoria das Situações (TS), que permitem uma modelagem, adaptação e teorização dos principais elementos envolvidos no contexto de ensino e aprendizagem em Matemática, entretanto, propugnamos ainda a incorporação dos pressupostos da (DP), em nosso país, visando um trato sistemático adequado com o escopo na compreensão do papel do professor e sua aprendizagem originada de situações profissionais (SP) e situações didáticas profissionais (SDP). Como já mencionamos, a influência dos estudos desenvolvidos no Brasil, com a contribuição teórica do campo de estudo da (DM), já tem quase trinta anos de repercussão. No entanto, apesar de sua aparição na França na década de 1990, a (DP) ainda não tem aplicação expressiva e sistemática visando uma pesquisa aplicada no Brasil, sobretudo, ao campo da formação de professores e a compreensão de sua evolução profissional.

Oriundo de uma forte herança piagetina e, acrescentamos, de uma forte herança e tradição em Psicologia (do Trabalho), a noção de situação constitui um elemento fundamental 
para o desenvolvimento de uma prática sistemática investigativa assumida no interior da (DP). Por sua vez, a (DM) conferiu um lugar de destaque, por exemplo, para noções emblemáticas de "situação didática" e "situação adidática". Não obstante, enquanto tais noções objetivam um grande interesse pelos processos que concorrem para a evolução das aprendizagens e habilidades dos estudantes, marcadamente determinada pelo saber matemático de referência (le savoir mathématique), nós concebemos a noção de situação didática profissional (SDP) que visa constituir um constructo teórico para a pesquisa em torno do interesse investigativo centrado na competência profissional do professor e a descrição e a modelização de situações de simulação que permitam colocar em evidencia elementos perceptuais inenerentes aos esquemas (cognitivos) desenvolvidos e mobilizados em situações práticas de sua atividade e aprendizagem do e no trabalho.

Finalmente, o viés de complementaridade que apresentamos ao leitor se coaduna com uma forte tradição e estilo epistêmico, introduzido em nosso país pela (DM) que, de modo recorrente, costuma apresentar uma discussão de fenômenos originados do ensino e da aprendizagem, a partir de um expediente que não assume um papel exclusivista e autônomo de um único referencial teórico. Dessa forma, a proposta que apresentamos, de um ponto de vista da complementaridade teórica ensejada, não determina ou consubstancia nenhum fator ou estilo de inedistismo, entretanto, nosso ponto de vista de complementaridade, com o uso da (DP) e da (DM) poderá delinear um intinerário investigativo até então não objetivado pelos especialistas e didatas, tanto em nosso pais, bem como no exterior.

Na figura 4 apresentamos um cenário mnemônico que visa situar o tetraedro de formação do professor, tanto no plano afetado pela (DP) (ver figura 4), como também, em um plano de contágio epistêmico com a (DM). Assumindo uma posição concorde com Baudoin (1999), propugnamos que o modelo tripolar introduzido por Brousseau (1986) não se mostra suficiente para nosso expediente teórico. 


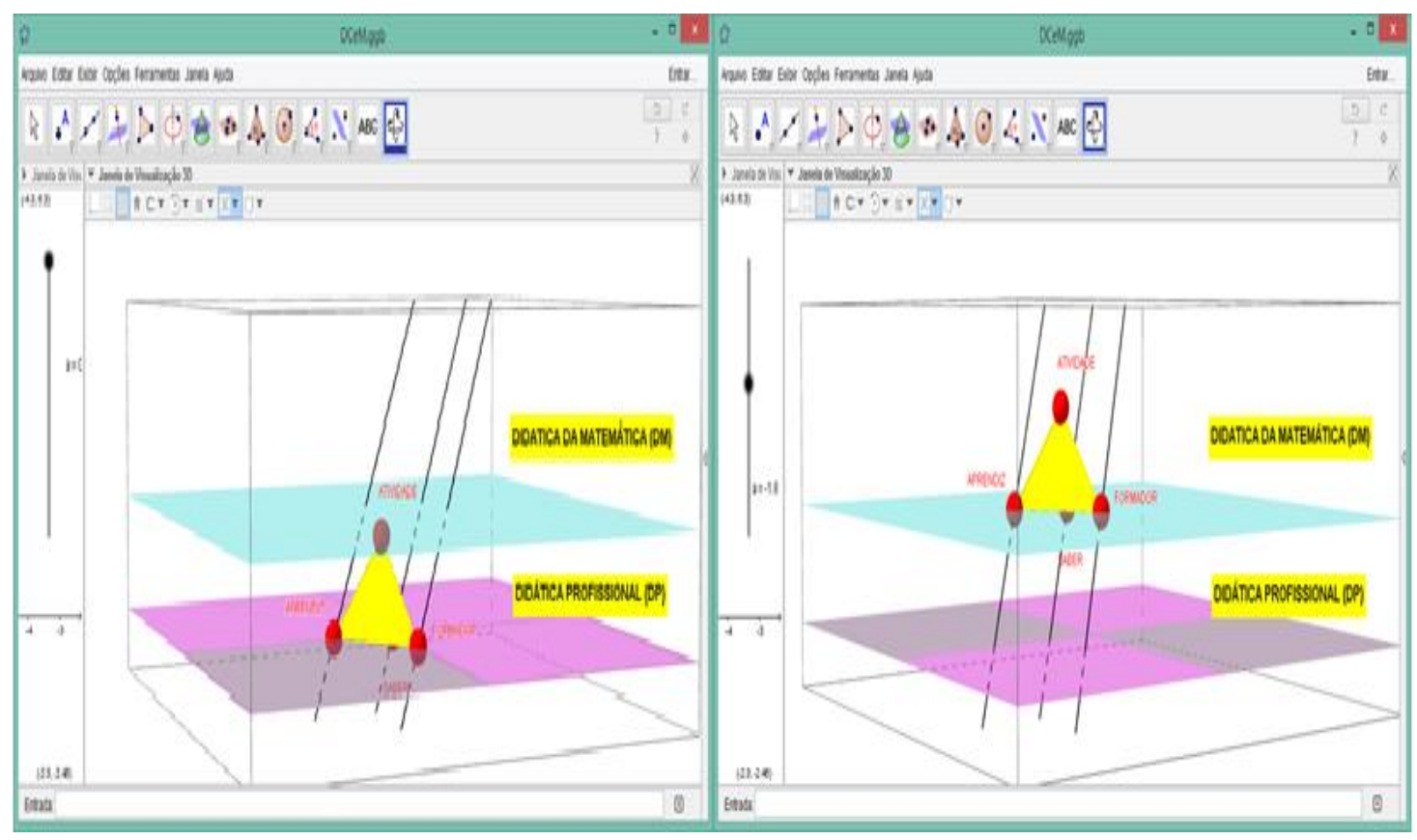

Figura 4. Descrição do triedro (3D) de formação condicionado e posicionado sob o plano da (DP) e do plano da (DM) (elaboração do autor)

Por fim, quando perspectivamos o trabalho dos professores, sobretudo, o trabalho dos mais experientes (experts), podemos constatar que determinadas rotinas e roteiros de ação e execução tendem ou se dirigem a um processo de simplificação, optimização, estilo profissional lacônico e, até mesmo, de economia ou encurtamento das ações, não raro, o seu envelhecimento também. Claramente, divisamos alguns princípios da Ergonomia cognitivista, posto que, nos interessamos pelos roteiros de simplificação progressiva e não perda de eficiência de aplicação de conhecimentos e a competência exigida para tais tarefas. Por outro lado, ao passo que divisamos princípios ergonômicos que atuam diretamente na sua praxis em sala de aula, observamos, também, princípios invariantes organizadores da ação em contexto ampliado de exercício do ofício da docência e no campo do trabalho que requerem um maior estádio cientifico de compreensão.

\section{Referências}

Almouloud, Ag Saddo. Fundamentos da Didática da Matemática. São Paulo: Editora UFPR, 2007.

Alves, F. R. V. (2019). A vertente frances de estudos da Didática Profissional: implicações para a atividade do professor de Matemática. Revista Vydia Educação, 39(1), 255 - 275. Disponível em: https://periodicos.ufn.edu.br/index.php/VIDYA/article/view/2459 
Alves, F. R. V. (2020). A Didática Profissional (DP): implicações para a formação do professor e o ensino de disciplinas específicas no Brasil. Revista Iberoamericana de Estudos em Educação, 15(4), $1902 \quad$ - $1918 . \quad$ Disponível em: https://periodicos.fclar.unesp.br/iberoamericana/article/view/13377

Alves, F. R. V. (2018a). Didactique Professionnelle (DP) et la Théorie des Situations Didactiques (TSD): le cas de la notion d'obstacle et 1'activité de professeur. EM TEIA: Revista de educação matemática e tecnológica ibero-americana. 9(2), 1 - 25.

Alves, F. R. V. (2018b). The professional didactics (PD) and didactics of sciences (DS) in brazil: some implications for the professionalization of the science teacher. Acta Didactica Naposcencia. 11(2), $105-120$.

Alves, F. R. V. (2018c). Mestrado (acadêmico) em ensino de ciências e matemática: a proposta do instituto federal do ceará (IFCE). Revista Contexto \& Educação, 33(2), 305 - 340.

Alves, F. R. V. (2018d). Engenharia Didática de Formação (EDF): sobre o ensino dos Números (Generalizados) de Catalan (NGC). Educação Matemática Pesquisa. 20(2), 47 - 83. Disponível em: https://revistas.pucsp.br/index.php/emp/article/view/36808

Alves, F. R. V. (2018e). Professional Didatics (PD): a perspective of application to wor of the mathematics teacher. REVEMAT, 13(2), $184-209$. Disponível em: https://periodicos.ufsc.br/index.php/revemat/article/view/1981-1322.2018v13n2p184

Alves, F. R. V. (2018f). Didactique des mathématique (DM) et la Didactique Professionelles (DP): une proposition de complementarité et la formation des enseignants au Brésil. Imagens da Educação. 8(3), 1 - 17. Disponível em: http://periodicos.uem.br/ojs/index.php/ImagensEduc/article/view/44179

Alves, F. R. V. (2017). Didática das ciências e matemática (dcem): surgimento e implicações para a formação do professor. Investigações em Ensino de Ciências. 22(3), 291 - 320. Disponível em: https://www.if.ufrgs.br/cref/ojs/index.php/ienci/article/view/870

Alves, F. R. V. (2016). Didática de matemática: seus pressupostos de ordem epistemológica, metodológica e cognitiva. Interfaces da Educação. 7(21), 131 - 150.

Artigue, M, Perrin-Glorian, M. J. (1991) Didactic engineering, research and development tool: some theoretical problems linked to this duality. Learn Math, 11(1), p. 13 - 17. Disponivel em: https://flmjournal.org/Articles/DCDCA6E791D990791426D7502008.pdf

Artigue, M. (1995). Ingeniería didáctica. In: Gomez, P. (1995). Ingeniería didáctica en educación matemática. 33 - $61 . \quad$ Disponível em: https://core.ac.uk/download/pdf/12341268.pdf

Artigue, M. (2009). Didactical design in mathematics education. Proceedings Nordic Research in Mathematics Education. Proceedings of NORMA08. 1 - 10. Disponível em: https://isis.ku.dk/kurser/blob.aspx?feltid=212293

Artigue, M. (2014). Didactic engineering in mathematics education. In S. Lerman (Ed.), Encyclopedia of mathematics education (p. 159-162). New York: Springer. 
Artigue, M. (2018). Didáctica de las matemáticas y reproducibilidad. Educación Matematica, 30(2), Disponível em: http://www.revista-educacionmatematica.org.mx/descargas/vol30/2/01_REM_30-2_Artigue.pdf

Barquero, B. \& Bosch, M. (2015). Didactic engineering as a research methodology: from fundamental situations to study and research paths. In A. Watson, M. Ohtani (eds.) Task Design in Mathematics Education, (pp. 249-272). Dordrecht: Springer.

Baudouin, Jean. M. (1999). La competénce et le théme de l'acitivité: vers une nouvelle conceptualization didactique de la formation. Raison éducative. 2(2), $149-168$. Disponível em: http://www.unige.ch/fapse/publicationsssed/files/4114/1572/5507/Pages_de_149_ENCOED.pdf

Boterf, G. L. (1999). Les défis posés à l'ingénieirie de formation et à la production des expertises collective. Quelles evolution prendre en compte? Quelles consequence pratiques. Journée d'Étude ingénierie dispositifs de formation à l'international. November, Monpellier. Disponivel em: https://www.agropolis.fr/formation/pdf/Le_Boterf.pdf

Brousseau, G. (1986a). La relation didactique: le milieu, Actes de la IVème Ecole d'Eté de didactique des mathématiques, (pp. 54-68), IREM Paris 7. Disponível em: http://math.unipa.it/ grim/brousseau_03_milieu.pdf

Brousseau, G. (1988). Perspective pour la didactique des mathématiques: vingt ans de didactique des mathématiques en France. Paris: La Pensée Sauvage, 5 - 66, 1994.

Brousseau, G. (1988). Les différents rôles du maître. Bulletin de l'A.M.Q. Montréal., 1988, 1424.

Brousseau, G. (1986b). Théorisation des phénomènes d'enseignement des mathématiques. (Thése de doctorat). Bourdeaux: Université Bourdeaux I.

Brousseau, G. (1998). Les obstacles épistémologiques, problèmes et ingénierie didactique. G. Brousseau, (org.). Théorie des situations didactiques. Grenoble La Pensée Sauvage, 115 $-160$.

Brousseau, G. (1986c). Education et didactique des mathématiques. Disponível em: https://hal.archives-ouvertes.fr/hal-00466260/document

Brousseau, G. (2000). Educación y didáctica de las matemáticas. Educación Matemática, 12(01), 5 - 38. Disponível em: http://www.revista-educacionmatematica.org.mx/descargas/Vol12/1/03Brousseau.pdf

Brousseau, G. (2004). L'émergence d'une science de la didactique des mathématiques. Repères IREM, $\mathrm{n}^{\circ} 55,19-34$.

Chevallard, Y. (1991). La transposition didactique. Paris: La pensée sauvage.

Chevallard, Y. (1991). La notion d'ingénierie didactique, un concept à refonder. 15e École d'Été de Didactique des Mathématiques. 1 - 44. Disponível em: Disponivel em: http://yves.chevallard.free.fr/spip/spip/IMG/pdf/Cours_de_YC_a_1_EE_2009.pdf

Douady, R. (1987). Jeux de cadres et dialectique outil objet. Recherches en didactique des mathématiques, 7/2, 5-31. 
Douady, R. (1995). La ingeniería didáctica y la evolución de su relación con el conocimiento. In: GOMEZ, P. (1995). Ingeniería didáctica en educación matemática. 33 - 61. Disponível em: https://core.ac.uk/download/pdf/12341268.pdf

Fernagu-Oudet, Solveig. (2004). Ingénierie de professionnalisation et didactique professionnelle. Recherche et Formation, no 46, 117 - 135. Disponível em: http://ife.enslyon.fr/publications/edition-electronique/recherche-et-formation/RR046-08.pdf

Fischbein, E. (1987). Intuition in science and mathematics: an educational approach, Netherlands: D. Reidel Public, Mathematics Educational Library.

Hebrard, P. (2011). L'ingenierie de formation: ce qui em releve et ce qui lui echappe. TransFormations, $109-119 . \quad$ Disponivel em: http://www.trigone.univlille1.fr/transformations/docs/tf05_a08.pdf

Joshua, S. \& dupin, J-J. (1993). Introduction à la Didactiques des Sciences et des Mathématiques. Paris: Presses Universitaires de France.

Leclercq. G. (2002). Quelques usages de l'activité d'ingénierie de formation. Savoirs 2003/2 (nº 2), p. 71-104. Disponível em: https://www.cairn.info/revue-savoirs-2003-2-page71.html

Leplat. J. (1983). Tache et activite dans 1'analyse psychologique des situations. Cahiers de Psychologie Cognitive. 3(1), $49-63 . \quad$ Disponível em: http://jeanmichelhoc.free.fr/pdf/LepHoc\%201983.pdf

Leplat. J. (1986). L’analyse psychologique du travail. Revue de Psychologie Appliquée. 36(1), $92-27 . \quad$ Disponível em: http://www.guillaumegronier.com/2014_psychologietravail/resources/Leplat_2004.pdf

Leplat. J. (2004). Éléments pour l'étude des documents prescripteurs. Revue Activités, 1(2), 195 - 216. Disponível em: https://journals.openedition.org/activites/1293

Leplat. J. (2003). Quelles evolutions en ergonomie ? In: XXXVIIIème Congrès de la SELF, Modèles et pratiques de l'analyse du travail. Paris, 1 - 15. Disponível em: https://ergonomie-self.org/publications/actes-des-congres/congres-2003/

Leplat. J. (2006). La notion de régulation dans l'analyse de l'activité. Revue Pistes. 8(1), 1 - 30. Disponivel em: http://journals.openedition.org/pistes/3101

Leplat. J. (2008). Les compétences dans l'activité et leur analyse. Psychology of Human Ressource Journal. 2(4), 143 - 154. Disponível em: http://pru.apio.ro/index.php/prujournal/article/view/188

Margolinas, C. (1988). Une etude sur les difficultes d'enseignement des nombres reels. La Revue Petit x. 2(16), 51 - 66. Disponível em: http://www-irem.ujfgrenoble.fr/revues/revue_x/fic/16/16x4.pdf

Margolinas, C. (2005). Essai de généalogie en didactique des mathématiques. Revue suisse des sciences de l'éducation. 27(3), 343 - 360. Disponível em: http://www.pedocs.de/volltexte/2011/4128/pdf/SZBW_2005_H3_S343_Margolinas_D _A.pdf 
Margolinas, C. Connaissance et savoir. (2014). Concepts didactiques et perspective sociologique? Revue française de pédagogie. 2(18, 13 - 22. Disponível em: https://journals.openedition.org/rfp/4530

Margolinas, C.; Drijvers, P. (2015). Didactical engineering in France: an insider's and and outsider's view on it's foundations, its practice and its impact. ZDM Mathematics Education, $47(3), \quad 893 \quad-\quad 403 . \quad$ Disponível em: https://link.springer.com/article/10.1007/s11858-015-0698-z

Mayen, P. (2012). Les situations professionnelles: un point de vue de didactique professionnelle. Revue Phronesis, 1(1), 59-67. Disponível em: http://www.fractaleformation.net/dmdocuments/Les-situations-professionnelles-P-Mayen.pdf

Mayen, P. (2007). Quelques repères pour analyser les situations dans lesquelles le travail consiste à agir pour et avec un autre. In: Fabre, M. Apprentissage et développement: apprendre, se former et agir. Recherche en Education, nº 4, October. 51 - 65. Disponível em: http://www.recherches-en-education.net/IMG/pdf/REE-no4.pdf

Mayen, P.; Metral, J. F. (2008). Compétences et validation des acquis de l'expérience. Revue française de sciences sociales. 4(11), $183-197$. Disponível em: https://journals.openedition.org/formationemploi/1175

Mayen, P.; Olry, P. \& Pastré, P. (2017). L’ingenierie didactique professionnelle, In Carré, P. \& Caspar, P. (2017); Traité des sciences et des techniques de la Formation - 4e édition. Paris : Dunod. pp. $1-12$.

Mayen, P. Gagneur, C. H. (2017). Le potentiel d'apprentissage des situations: une perspective pour la conception de formations en situations de travail. In: Metral. J. F. Penser la didactique pour la formation professionnelle. $\mathrm{n}^{\mathrm{o}} 28$, mars, $70-84$.

Mayen, P.; Pin, J. P. (2013). Conditions et processus de l'engagement en VAE. Revue française de sciences sociales. 4(122), $13-29 . \quad$ Disponível em: https://journals.openedition.org/formationemploi/3981

Mayen, P.; Savoyant, A. (2002). Formation et prescription: une réflexion de didactique professionnelle. Nouvelles formes de travail, nouvelles formes d'analyse. 226 - 232. 2002. Disponível em: https://ergonomie-self.org/wp-content/uploads/2016/01/congresself-2002-aix-mayen-savoyan-formation-prescription-didactique.pdf

Mayen, P.; Olry, P. (2012). Expérience du travail et développement pour de jeunes adultes en formation professionnelle. Recherche et formation. 12(70), 91 - 106. Disponível em: http://journals.openedition.org/rechercheformation/1872

Mayen, P., Metral, J.F. \& Tourmen, C. (2010). Les situations de travail: références pour les référentiels. Recherche et formation, 64, 31-46. Disponível em: https://halshs.archivesouvertes.fr/halshs-01688338/document

Montmollin, Maurice. (2003). Identité des ergonomes, identité des ergonomies: Quelles compétences pour quelles activités ? In: XXXVIIIème Congrès de la SELF, Modèles et pratiques de l'analyse du travail. Paris, 15 - 24. Disponível em: https://ergonomieself.org/publications/actes-des-congres/congres-2003/ 
Munoz, G. (2007). L'analyse de quelques «mouvements cognitifs » entre les différentes formes de la connaissance: repères pour la formation. In: Fabre, M. Apprentissage et développement: apprendre, se former et agir. Recherche en Education, $\mathrm{n}^{\mathbf{o}}$ 4, October. 39 - 51. Disponível em: http://www.recherches-en-education.net/IMG/pdf/REE-no4.pdf

Olry, P. (2002). Apprentissages opportunistes au travail, Revue française de pédagogie, 2(18), 19 - 28. Disponível em: http://ife.ens-lyon.fr/publications/edition-electronique/revuefrancaise-de-pedagogie/INRP_RF138_3.pdf

Olry, P. (2008). Apprendre au travail. Inscription sociale de la didactique professionnelle. 2008. Disponível em: https://tel.archives-ouvertes.fr/tel-00725325/document

Olry, P. (2012). La situation professionnelle: entre invariance et perspective?. Phronpesis. 1(1), janvier, 68 - 84. Disponível em: https://www.erudit.org/fr/revues/phro/2012-v1-n1phro1825121/1006485ar.pdf

Olry, P. (2009). L'experience du travail comme indicateur de développment. Recherche en Éducation. 5(11), $194 \quad$ - 208, 2009. Disponível em: http://journals.openedition.org/questionsvives/584

Piaget, J. (1947). La représentation du monde chez l'enfant. Paris: PUF.

Parmentier. C. (2008). L'ingénierie de formation. Paris: Édition EYROLLES. Disponível em: http://avoirplus.yolasite.com/resources/L'ingenierie\%20de\%20formation.pdf

Paquette, G. (2004). L'ingénierie pédagogique à base d'objets et le référencement par les compétences. International Journal of Technologies in Higher Education. 4(3), 45 - 55. Disponível em: http://www.ritpu.org:81/img/pdf/art4Paquette.pdf

Pastré, P. (2002). L'analyse du travail en Didactique professionnelle. Revue Française de Pédagogie, $\quad 3(13), \quad 9 \quad-\quad$ 17. $\quad 9$ Disponível em: http://www.formations.philippeclauzard.com/INRP_RF138_2.pdf

Pastré, P. (2001). Analyse du travail et didactique professionnelle. Acta Rencontre Analyse du travail et Didactique Professionnelles, CAFOC de Nantes. 1 - 17. Disponível em: http://www.fractale-formation.net/dmdocuments/analyse-du-travail-et-DPconf\%C3\%A9rence-de-Pastr\%C3\%A9-2001.pdf

Pastré, P. (2007a). Analyse du travail et formation. In: Fabre, M. Apprentissage et développement: apprendre, se former et agir. Recherche en Education, $\mathrm{n}^{\circ}$ 4, October. 23 - 29. Disponível em: http://www.recherches-en-education.net/IMG/pdf/REE-no4.pdf

Pastré, P. (2011). La Didactique Professionelle. Education, Sciences \& Society, 2(1), 83 - 95. Disponível em: https://riviste.unimc.it/index.php/es_s/article/view/136/65

Pastré, P. (2004). Les compétences professionnelles et leur développement, 213 - 231, In: Faizon, P. Ergonomie. Paris: PUF. Disponível em: http://benhur.teluq.uquebec.ca/SPIP/inf4018/IMG/pdf/Pastre.pdf

Pastré, P. (2007b). La didactiques Professionnelles. [filme - vídeo], Le Web TV formation professionnelles. AFPA, Paris. 54mim. 2007b. Disponível em: http://pros.webtv.afpa.fr/tfs/accueil/1495/res:La-didactique-professionnelle 
Pastré, P. (2017). A análise do trabalho em didática profissional. Revista bras. Estud. Pedagógicos. 98(25), $624 \quad-\quad 637 . \quad$ Disponível em: http://rbep.inep.gov.br/index.php/rbep/article/view/3368

Perrin-Glorian, M-J; Bellemain, P. M. B. (2016). L'ingenierie didactique entre recherche et ressource pour l'enseignement et la formation des maitres. Anais do I Simpósio LatinoAmericano de Didática da Matemática. 1 - 35.

Perrin-Glorian, M.J. (2011). L'ingénierie didactique à l'interface de la recherche avec l'enseignement. Développement de ressources et formation des enseignants. In C. Margolinas et al. (éds.) En amont et en aval des ingénieries didactiques. pp. 57-78. Grenoble: La pensée sauvage.

Perrin-Glorian, M. J. (2012). Quelques réflexions sur l'enseignement des nombres et grandeurs au long de la scolarité obligatoire. Educmath. Available from http://educmath.enslyon.fr/Educmath/dossier-manifestations/conferencenationale/contributions/conference-nationale--perrin-glorian

Perrin-Glorian, M.J. (1993) Questions didactiques soulevées à partir de l'enseignement des mathématiques dans des classes faibles, Recherches en didactique des mathématiques, 13/1.2, 5-18. Disponível em: http://www-irem.ujfgrenoble.fr/revues/revue_x/fic/35/35x1.pdf

Pastré, P.; Mayen, P.; Vergnaud, G. La didactique professionnelle. Revue française de pédagogie. 154(1), janvier, $145-198,2006$. Disponível em: https://journals.openedition.org/rfp/157

Prost, A. (1999). L'evolution de la formation des enseignants de 1960. Rccherche et Formation. $\mathrm{n}^{\mathrm{o}} \quad 32,9-24 . \quad$ Disponível em: http://ife.ens-lyon.fr/publications/editionelectronique/recherche-et-formation/RR032-02.pdf

Perrin-Glorian, M - J. Questions didactiques soulevées à partir de l'enseignement des mathématiques dans des classes faibles, Recherches en didactique des mathématiques, 13/1.2, 5-118, 1993. Disponível em: http://www-irem.ujfgrenoble.fr/revues/revue_x/fic/35/35x1.pdf

Robert, A.; Rogalski, M. (2004). Problemes d'introduction et autres problemes de recherche au lycee. REPERES - IREM. $\mathrm{n}^{\circ} 54$ - janvier, 1 - 27. Disponível em: http://www.univirem.fr/exemple/reperes/articles/54_article_380.pdf

Robinet, J. (1983). De l'Ingenierie didactique. Les Cahier Blanc, 1 - 11. Disponível em: http://www.irem.univ-paris-diderot.fr/up/CDM_1_Jacqueline_Robinet__De_ling\%C3\%A9nierie_didactique.pdf

Sauriau, P. (1881). Théorie de l'invention, Paris: Librarie Hachette. Disponível em: https://gallica.bnf.fr/ark:/12148/bpt6k5460195f?rk=21459;2

Tempier, F. (2013). La numération décimale de position à l'école primaire. Une ingénierie didactique pour le développement d'une ressource. (Thése de doctorat). Paris: Université Dennis Diderot. Paris 7. Disponível em: https://tel.archives-ouvertes.fr/tel$\underline{00921691}$ 
Vergnaud, G. (2007). Les compétences en milieu professionnel. Journée d'étude Formation de Formateurs. Paris, p. 1 - $\quad 6 . \quad$ Disponível em: http://ressources.creteil.iufm.fr/fileadmin/documents/siteFFO/Service/Productions/200 7_Je_2_G_Vergnaud.pdf

Vergnaud, G. (2001). Forme opératoire et forme prédicative de la connaissance. Conférence publiée dans les Actes du Colloque GDM-2001. Disponível em: http://www.recherches.philippeclauzard.com/vergnaud_forme_connaissance.pdf

Vergnaud, G. (2007b). Représentation et activité: deux concepts étroitement associes. Recherche et Education, $\mathrm{n}^{\mathrm{o}}$ 4, October, $1-11$, 2007b. Disponível em: https://isfecauvergne.org/IMG/pdf/article_de_Vergnaud.pdf

Tourmen, C. (2014). Usages de la didactique professionnelle en formation: principes et évolutions. Savoirs, 36(2), 9-40. Disponível em: https://www.cairn.info/revue-savoirs2014-3-page-9.htm

Yvon, F.; Clot, Y. (2004). Apprentissage et développement dans l'analyse du travail enseignant. Revista de Psicologia da Educação, 19)2), 11 - 38 . Disponível em: http://pepsic.bvsalud.org/pdf/psie/n19/n19a02.pdf

\section{Agradecimentos}

Agradecemos ao apoio e suporte financeiro concedido no Brasil pelo Conselho Nacional de Desenvolvimento Científico e Tecnológico - CNPQ para o desenvolvimento dessa pesquisa.

Autor:

Francisco Regis Vieira Alves. Possui graduação em Bacharelado em Matemática pela Universidade Federal do Ceará (1998), graduação em Licenciatura em Matemática pela Universidade Federal do Ceará (1997), mestrado em Matemática Pura pela Universidade Federal do Ceará (2001) e mestrado em Educação, com ênfase em Educação Matemática, pela Universidade Federal do Ceará (2002). Doutorado com ênfase no ensino de Matemática (UFC

- 2011). Atualmente é professor TITULAR do Instituto Federal de Educação Ciência e

Tecnologia do estado do Ceará/ IFCE - 40h/a com DE, do curso de Licenciatura em

Matemática. Tem experiência na área de Matemática e atuando principalmente nos seguintes temas: Didática da matemática, História da Matemática, Análise Real, Filosofia da Matemática e Tecnologias aplicadas ao ensino de matemática para o nível superior. Com pesquisa voltada ao ensino de Cálculo I, II, III, Análise Complexa, EDO, Teoria dos Números.

E na Universidade Aberta do Brasil, com o ensino a distância de Matemática. Desenvolve pesquisa direcionada para o ensino do Cálculo a Várias Variáveis e sua transição interna. Atua também no Mestrado Profissional em Ensino de Ciências e Matemática (ENCIMA) - UFC.

Revisor e parecerista ad hoc dos seguintes periódicos: Vydya Educação, Sinergia - IFSP, Rencima - Revista de Ensino de Ciências e Matemática, Revista do Instituto Geogebra de São

Paulo, Tear - Revista de Educação, Ciência e Tecnologia, Boletim Online de Educação Matemática - BoEM e revista REMAT: Revista Eletrônica da Matemática. Comitê editorial do Boletim Cearense de Educação e História da Matemática (BOCEHM) e Coordenador do Programa de Pós Graduação em Ensino de Ciências e Matemática - PGECM/IFCE (acadêmico). no período de 2015/2020 e Membro do Consenho Científico da revista ForSCience - IFMG. Avaliador da EURASIA Journal of Mathematics, Science and Technology Education 